\title{
Safety and efficacy assessment of standardized herbal formula PM012
}

Sung-Hwa Sohn ${ }^{1 \dagger}$, Soo-Jeong Kim ${ }^{1,2+}$, Yong Kim ${ }^{1}$, Insop Shim ${ }^{1}$ and Hyunsu Bae ${ }^{1 *}$

\begin{abstract}
Background: This study was conducted to evaluate the efficacy of the herbal formula PM012 on an Alzheimer's disease model, human presenilin 2 mutant transgenic mice (hPS2m), and also to evaluate the toxicity of PM012 in Sprague-Dawely rats after 4 or 26 weeks treatment with repeated oral administration.

Methods: Spatial learning and memory capacities of hPS2m transgenic mice were evaluated using the Morris Water Maze. Simultaneously, PM012 was repeatedly administered orally to male and female SD rats (15/sex/group) at doses of 0 (vehicle control), 500, 1,000 and 2,000 mg/kg/day for 4 or 26 weeks. To evaluate the recovery potential, 5 animals of each sex were assigned to vehicle control and 2,000 mg/kg/day groups during the 4-week recovery period.

Results: The results showed that PM012-treated hPS2m transgenic mice showed significantly reduced escape latency when compared with the hPS2m transgenic mice. The repeated oral administration of PM012 over 26 weeks in male and female rats induced an increase and increasing trend in thymus weight in the female treatment groups (main and recovery groups), but the change was judged to be toxicologically insignificant. In addition, the oral administration of the herbal medicine PM012 did not cause adverse effects as assessed by clinical signs, mortality, body weight, food and water consumption, ophthalmology, urinalysis, hematology, serum biochemistry, blood clotting time, organ weights and histopathology. The No Observed Adverse Effects Levels of PM012 was determined to be $2,000 \mathrm{mg} / \mathrm{kg} /$ day for both sexes, and the target organ was not identified.
\end{abstract}

Conclusion: These results suggest that PM012 has potential for use in the treatment of the Alzheimer's disease without serious adverse effects.

Keywords: PM012, Repeated oral toxicity, Presenilin 2, NOAEL, Morris water maze, Spatial memory

\section{Background}

Alzheimer's disease (AD) is the major cause of dementia and underlies more than $60 \%$ of dementia cases [1]. AD occurs more frequently in older age groups [2]. AD is characterized by the impairment of cognitive performance such as attention, memory and learning, in addition to changes in cholinergic markers, including levels of acetylcholine (ACh) and choline acetyltransferase (ChAT) [3-5]. In addition, $\beta$-amyloid precursor protein $(\beta-A P P)$, Presenilin 1 (PS1), Presenilin 2 (PS2), and apolipoprotein $\mathrm{E}$ type 4 (APOE-E4) mutations are linked to the early onset of $\mathrm{AD}$ [6-10]. Of these, the mutated PS

\footnotetext{
* Correspondence: hbae@khu.ac.kr

+ Contributed equally

'Department of Physiology, College of Oriental Medicine, Kyung Hee

University, Hoegi-dong, Seoul, Dongdaemun-gu 130-701, Republic of Korea Full list of author information is available at the end of the article
}

genes were observed in the highest proportion of early AD patients $[6,11]$.

Herbal medicines are used for the prevention and treatment of various diseases. For example, Ginkgo biloba, Ginseng and Melisa officinalis have been commonly used as memory or cognition enhancers. The effects of these enhancers have been demonstrated scientifically [12-14]. Yukmijihwang-tang or Luweidihuang-wang (YMJ) is composed of 6 herbal medicines, Corni fructus, Rehmannia radix, Hoelen, Discoreae radix, Mountain cortex radicis and Alismatis radix. YMJ has long been applied to the treatment of diabetes mellitus and neurosis. Ancient Chinese herbal textbooks also reference $\mathrm{YMJ}$ as an anti-aging treatment. In a previous study, YMJ derivatives (PM012) containing Lycii fructus, in addition to the other components of YMJ, enhanced

\section{Biomed Central}


memory retention by protecting neuronal cells and enhancing cell proliferation and neurite growth [15]. In addition, PM012 accelerated the speed of information processing and enhanced cognitive abilities in normal subjects [16]. It has also been reported that PM012 treatment prevents the loss of cholinergic cells through anti-oxidative and anti-inflammatory effects, recovers reduced ChAT in the medial septum and improves overall spatial learning ability and the working memory deficits produced by ibotenic acid [17-19]. However, because the chemically induced dementia models do not mimic the pathophysiology of Alzheimer's disease in humans, it is necessary to evaluate a more clinically relevant and straightforward disease model such as hPS2m transgenic mice. Further, there are no reports regarding the safety of YMJ or PM012 to date. Therefore, we here report the results of our investigation of the safety and efficacy of the PM012 extract in rodents. This study was conducted in compliance with the Good Laboratory Practice (GLP) [20] and Test Guidelines of the Organization for Economic Cooperation and Development (OECD) [21] and U.S. Food and Drug Administration (FDA)[22] and the Korea Food and Drug Administration (KFDA) [23].

\section{Methods}

\section{Transgenic mice}

The human presenilin 2 (hPS2) mutant (N141I) transgenic mice (hPS2m) were generously provided by the National Institute of Toxicological Research (Korea FDA) and housed in a controlled environment (12:12hour light:dark cycle, temperature $23 \pm 2^{\circ} \mathrm{C}$, humidity 50 $\pm 10 \%)$ with water and food available ad libitum. The mice were randomly assigned to two groups (4-5 mice in each group), defined as follows: group 1: hPS2m tg; group 2: hPS2m tg + drug treatment. The hPS2m transgenic mice received a commercial mice chow, while the drug treated-hPS2m transgenic mice had access to chow containing 2\% PM012. They were each fed their respective chow from 32 to 48 weeks of age during the growing period. All experiments in this study were approved by the Institutional Animal Care and Use Committee of Kyung Hee University.

\section{Morris water maze test}

A modified version of the procedure described by Morris was used [24]. The water maze was a circular pool $1.5 \mathrm{~m}$ in diameter, constructed of fiberglass. The pool contained water maintained at a temperature of $22 \pm 2^{\circ}$ $\mathrm{C}$ and contained $1 \mathrm{~kg}$ of powdered skim milk to make the water opaque. During the testing in the water maze, a platform (15 cm in diameter) was fixed at $1 \mathrm{~cm}$ below the surface of the water at identical locations within the pool. The pool was surrounded by different extra-maze cues. Each trial was initiated at one of different starting positions and the route taken out of the pool and swimming path of each rat were recorded with a video camera connected to a video recorder and a tracking device (S-MART, Pan-Lab, Spain). All mice were subjected to four trials per day at intervals of 15 min for four consecutive days followed by one day of probe trials on the fifth day. The trials were considered to be completed when the rat found the hidden platform or the escape latency reached $60 \mathrm{~s}$. For the probe trial, the platform was removed from the pool and the rat was allowed to swim freely for $60 \mathrm{~s}$ to search for the previous location of the platform. The proportion of time spent searching for the platform in the training quadrant, i.e. the previous location of the platform, was used as a measure of memory retention.

\section{Animal maintenance for the toxicity test}

According to the Korea FDA guideline, we selected Sprague Dawley (SD) rats for toxicity assessment. Seventy male and seventy female SD rats, 5 weeks old, were obtained from Koatec Co. Ltd (Gyeonggi-do, Korea). Rats were acclimated in a controlled room (temperature: $23 \pm 3^{\circ} \mathrm{C}$, relative humidity: $55 \pm 15 \%$, air circulating frequency: 10-20 times/hr, artificial light: from 8 am to 8 pm) for 7 days before experimentation. Rats were housed in stainless steel cages (W215 $\times$ L355 $\times \mathrm{H}$ $200 \mathrm{~mm}$ ). Animals were offered irradiation-sterilized pellet food for lab animals (Harlan Co. Ltd, USA), purchased from FOLAS international Inc., ad libitum. According to the certificates evaluating the diet components and contaminants supplied by the diet provider, there were no factors in the chow that could affect the results of this study. Groundwater disinfected by ultraviolet sterilizer and ultrafiltration was given via water bottle ad libitum. The experimental protocols for this study were approved by the Institutional Animal Care and Use Committee, and the animals were cared for in accordance with the institutional ethical guidelines.

\section{Preparation of PM012}

Water-extracted dried herbal medicines were purchased from Sun Ten Pharmaceutical (Taipei, Taiwan). The ratio of each component in PM012 is shown in Table 1. The amount of standard phytochemicals of each herbal medicine was determined by an HPLC-based quantification method (Table 1).

\section{Experimental design for toxicity test}

Animals were randomly divided into six groups consisting of 15 or 5 rats of each gender. Group I animals (control) were administered distilled water (DW) by gavage throughout the course of the study. Animals in Groups II (500 mg/kg body weight/day), III (1000 mg/ 
Table 1 The contents of PM012 and the amounts of standard materials

\begin{tabular}{llll}
\hline Herbal medicines & Ratio (\%) & Standard materials & Standard material contents (mg/PM012 g ext.) \\
\hline Lycii fructus & $4(26.5 \%)$ & Betain & $0.32 \pm 0.02(0.03 \%)$ \\
Rehmannia radix & $4(26.5 \%)$ & $5-\mathrm{HMF}$ & $0.20 \pm 0.02(0.02 \%)$ \\
Corni fructus & $2(13 \%)$ & Loganin & $1.29 \pm 0.05(0.13 \%)$ \\
Discoreae radix & $2(13 \%)$ & Allantoin & $1.31 \pm 0.21(0.13 \%)$ \\
Hoelen & $1(7 \%)$ & & \\
Alismatis radix & $1(7 \%)$ & & \\
Mountain cortex radicis & $1(7 \%)$ & Paeonol & $0.93 \pm 0.033(0.09 \%)$ \\
\hline
\end{tabular}

$\mathrm{kg}$ body weight/day), IV (2000 $\mathrm{mg} / \mathrm{kg}$ body weight/day), V (recovery control) and VI (recovery group, $2000 \mathrm{mg} /$ $\mathrm{kg}$ body weight/day) received orally administered PM012 dissolved in DW by gastric intubation for a period of 4 or 26 weeks. Urinalyses were conducted during the last 4 days of the administration period. The urine of each group of animals was collected for $24 \mathrm{~h}$ and the volume of urine was measured. Animals were individually placed in metabolic cages in batches for a period of $24 \mathrm{~h}$ and were provided with water but not food. The animals were only fasted in metabolic cages for a period of $24 \mathrm{~h}$. Food and water were provided ad libitum during the other 3 days of sampling of the other groups. Following the observation period, all animals were anesthetized with $5 \mathrm{mg} / \mathrm{kg}$ of ketamine $\mathrm{HCl}$ intramuscularly (Ketamine ${ }^{\circledR}$, Yuhan Co., Korea). An autopsy was conducted on every animal and all major organs and tissues including heart, lung, liver, stomach, intestine, kidney, adrenal gland, spleen and ovary or testicle were examined for gross lesions.

\section{Clinical observations and survival}

Rats were observed twice daily (morning and afternoon) for signs of clinical toxicity and mortality. Body weights were recorded daily throughout the study period. Mean daily food consumption was calculated each day by subtracting the weight of the remaining food from the weight of the supplied food. Clinical examinations were performed twice daily, first at the time of dose administration and again approximately $1-2 \mathrm{~h}$ following dose administration. Observations included changes in skin, fur, eyes, oral mucosa, respiration, circulation and behavior.

\section{Urinalysis}

In the last week of observation, 15 animals per group were housed in a metabolic cage for urine collection, and approximately $1 \mathrm{ml}$ of fresh urine collected over 3-4 hours was analyzed by urinalysis test strips (Multistix 10SG, Bayer, USA) and an automatic analyzing instrument (CliniTek 100, Bayer, USA). The following parameters were analyzed: glucose, bilirubin, ketone bodies, specific gravity, occult blood, $\mathrm{pH}$, protein, urobilinogen, nitrite and leukocytes. Samples were also examined microscopically for the presence of urinary sediments, including erythrocytes, leukocytes, epithelial cells and cast.

\section{Hematology and serum biochemistry}

Blood samples were measured for clotting time, red blood cell (RBC) and white blood cell (WBC) counts, hemoglobin $(\mathrm{Hb})$, hematocrit $(\mathrm{HCT})$, mean corpuscular volume $(\mathrm{MCV})$, mean corpuscular $\mathrm{Hb}(\mathrm{MCH})$, mean corpuscular $\mathrm{Hb}$ concentration $(\mathrm{MCHC})$, red cell distribution width (RDW), Hb concentration distribution width (HDW), reticulocytes (RET), platelets (PLT), mean platelet volume (MPV), large unstained cells (LUC), neutrophils (NEU), lymphocytes (LYM), monocytes (MONO), eosinophils (EOS), and basophils (BASO) with a Coulter counter (ADVIA 2120, SIEMENS, USA) according to the manufacturer's operator manual. Serum from blood samples collected in separator tubes was analyzed for changes in biochemistry using an AU400 Serum biochemistry analyzer (AU400, Olympus, Japan), which measured aspartate aminotransferase activity (AST), alanine aminotransferase activity (ALT), alkaline phosphatase activity (ALP), creatine phosphokinase activity (CPK), total bilirubin (BIL), glucose (GLU), total cholesterol ( $\mathrm{CHO})$, triglycerides (TG), total protein (PRO), albumin (ALB), the albumin/globulin ratio (A/G ratio), blood urea nitrogen (BUN), creatinine (CRE), and inorganic phosphorus (IP). The concentrations of calcium ions $\left(\mathrm{Ca}^{2+}\right)$, sodium ions $\left(\mathrm{Na}^{+}\right)$, potassium ions $\left(\mathrm{K}^{+}\right)$, and chloride ions $\left(\mathrm{Cl}^{-}\right)$were measured with an electrolyte autoanalyzer (RAPIDCHEM $744 \mathrm{Na}^{+} / \mathrm{K}^{+} / \mathrm{Cl}^{-}$Analyzer, SIEMENS, USA).

\section{Blood clotting time assessment}

A total of $1.8 \mathrm{~mL}$ of blood was dispensed into a microtube containing $0.2 \mathrm{~mL} 3.2 \%$ sodium citrate. Plasma was obtained by centrifugation at $735 \times \mathrm{g}$ (5402, Eppendorf, Germany, 3,000 rpm, $735 \mathrm{RCF}$ ) at $4^{\circ} \mathrm{C}$ for $10 \mathrm{~min}$. Prothrombin time (PT) and activated partial thromboplastin time (APTT) were measured in seconds from the plasma using the nephelometric analysis method with a 
coagulation time analyzer (ACL 100, Instrumentation Laboratory, USA).

\section{Organ weights}

During the necropsy, the organs such as ovaries (both), uterus, adrenal glands (both), pituitary gland, thymus, prostate gland, testes (both), epididymides (both), spleen, kidneys (both), heart, lungs, brain, and liver were weighed with an electronic balance, and all the paired organs were measured separately. The weights of these organs were converted to relative organ weights based on the organ-to-body weight ratio.

\section{Fixation and storage of organs}

Eye balls were fixed in Davidson's solution, and testes and epididymides were fixed in Bouin's solution. The following organs of all animals were fixed in 10\% neutral formalin: testes, epididymides, seminal vesicles, prostate gland, ovaries, uterus, vagina, urinary bladder, spleen, stomach, pancreas, duodenum, jejunum, ileum, cecum, colon, rectum, mesenteric lymph node, adrenal glands, kidneys, liver, skeletal muscle, sciatic nerve, femur, submandibular lymph nodes, salivary glands, sternum, thymus, heart, lungs, aorta, thoracic spinal cord, tongue, trachea, esophagus, thyroid glands, harderian glands, eyes, brain, pituitary gland, and skin (mammary glands).

\section{Histopathological assessment}

The fixed organs of the vehicle control and high dose group and any organs from the other groups that displayed gross abnormalities were subjected to histopathological examination. Tissues were embedded in paraffin and microsections of 4-5 $\mu \mathrm{m}$ were taken from the block. Hematoxylin \& Eosin-stained slides were prepared and the specimens were microscopically examined with an optical microscope.

\section{Statistical analysis}

Statistical analysis of the data was conducted using SPSS 10.1. Data were analyzed by an unpaired $t$-test or twoway ANOVA or one-way analysis of variance (ANOVA) followed by the Dunnett multiple comparisons test. Results with a p-value $<0.05$ were considered statistically significant.

\section{Results}

\section{Efficacy assessment}

Effects of PM012 on the body weight of hPS2m transgenic mice

To determine whether PM012 treatment causes side effects, we measured its effects on body weight. As shown in Figure 1, there were significant differences in body weight between the hPS2 $\mathrm{m}$ transgenic mice and the drug treated-hPS2m transgenic mice $[\mathrm{F}(1,70)=$

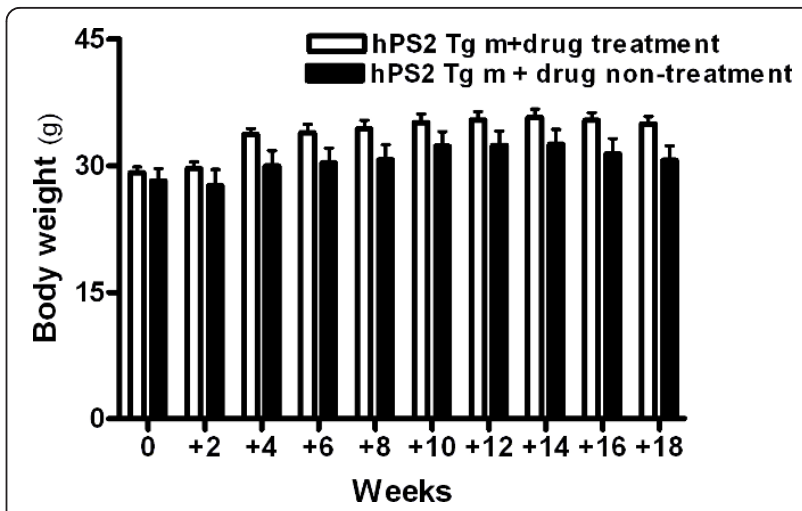

Figure 1 Change of the body weight of the experimental mice. The body weight of the hPS2 transgenic mice and the drug treated-hPS2 transgenic mice at $0,2,4,6,8,10,12,14,16$ and 18 days following drug treatment ( $n=4-5 /$ group). The data shown are the means \pm S.E.M ( $n=7-8 /$ group).

21.21, $\mathrm{p}<0.001]$. The increase in body weight over the experimental period was significantly higher in the drug treated-hPS2 transgenic mice compared to the hPS2m transgenic mice $(t$-test; $\mathrm{t}=3.387, \mathrm{df}=18, \mathrm{p}=0.0033)$. The average body weight of the hPS2m transgenic mice versus the drug treated-hPS $2 \mathrm{~m}$ transgenic mice was $23.180 \pm 1.476 \mathrm{~g}$ versus $29.175 \pm 0.638 \mathrm{~g}$ at 0 week, $27.620 \pm 1.930 \mathrm{~g}$ versus $29.625 \pm 0.819 \mathrm{~g}$ at 2 weeks, $29.940 \pm 1.857 \mathrm{~g}$ versus $33.675 \pm 0.735 \mathrm{~g}$ at 4 weeks, $30.320 \pm 1.777 \mathrm{~g}$ versus $33.900 \pm 0.998 \mathrm{~g}$ at 6 weeks, $30.680 \pm 1.810 \mathrm{~g}$ versus $34.375 \pm 1.005 \mathrm{~g}$ at 8 weeks, $32.300 \pm 1.731 \mathrm{~g}$ versus $35.100 \pm 1.027 \mathrm{~g}$ at 10 weeks, $32.420 \pm 1.704 \mathrm{~g}$ versus $35.400 \pm 1.002 \mathrm{~g}$ at 12 weeks, $32.540 \pm 1.745 \mathrm{~g}$ versus $35.700 \pm 0.99 \mathrm{~g}$ at 14 weeks, $31.420 \pm 1.774 \mathrm{~g}$ versus $35.375 \pm 0.923 \mathrm{~g}$ at 16 weeks and $31.420 \pm 1.774 \mathrm{~g}$ versus $34.975 \pm 0.863 \mathrm{~g}$ at 18 weeks.

PM012 reverses spatial learning deficits at 12 months of age in hPS2m transgenic mice

To determine whether PM012 treatment affects spatial memory tasks, we evaluated its effects on learning and memory in hPS2 $\mathrm{m}$ transgenic mice using the Morris water maze test. In this study, drug treatment had a significant effect on escape latency (i.e., the swimming time required to find a hidden platform in the acquisition test) and total swimming distance (i.e., the swim path length taken to find the hidden platform in the acquisition test) among the hPS2m transgenic mice. The memory deficiency exhibited by mice with the hPS $2 \mathrm{~m}$ mutation was significantly alleviated in the drug treatedhPS $2 \mathrm{~m}$ transgenic mice when compared with the untreated hPS $2 \mathrm{~m}$ transgenic mice. As shown in Figure $2 \mathrm{~A}$ and $2 \mathrm{~A}^{\prime}$, analysis of the escape latency revealed a significant difference between groups $[F(1,21)=2.963$, $p$ $<0.05]$ and depending on the time of day $[\mathrm{F}(3,21)=$ $5.9, \mathrm{p}<0.01]$. On days $1-4$, the drug treated-hPS2 

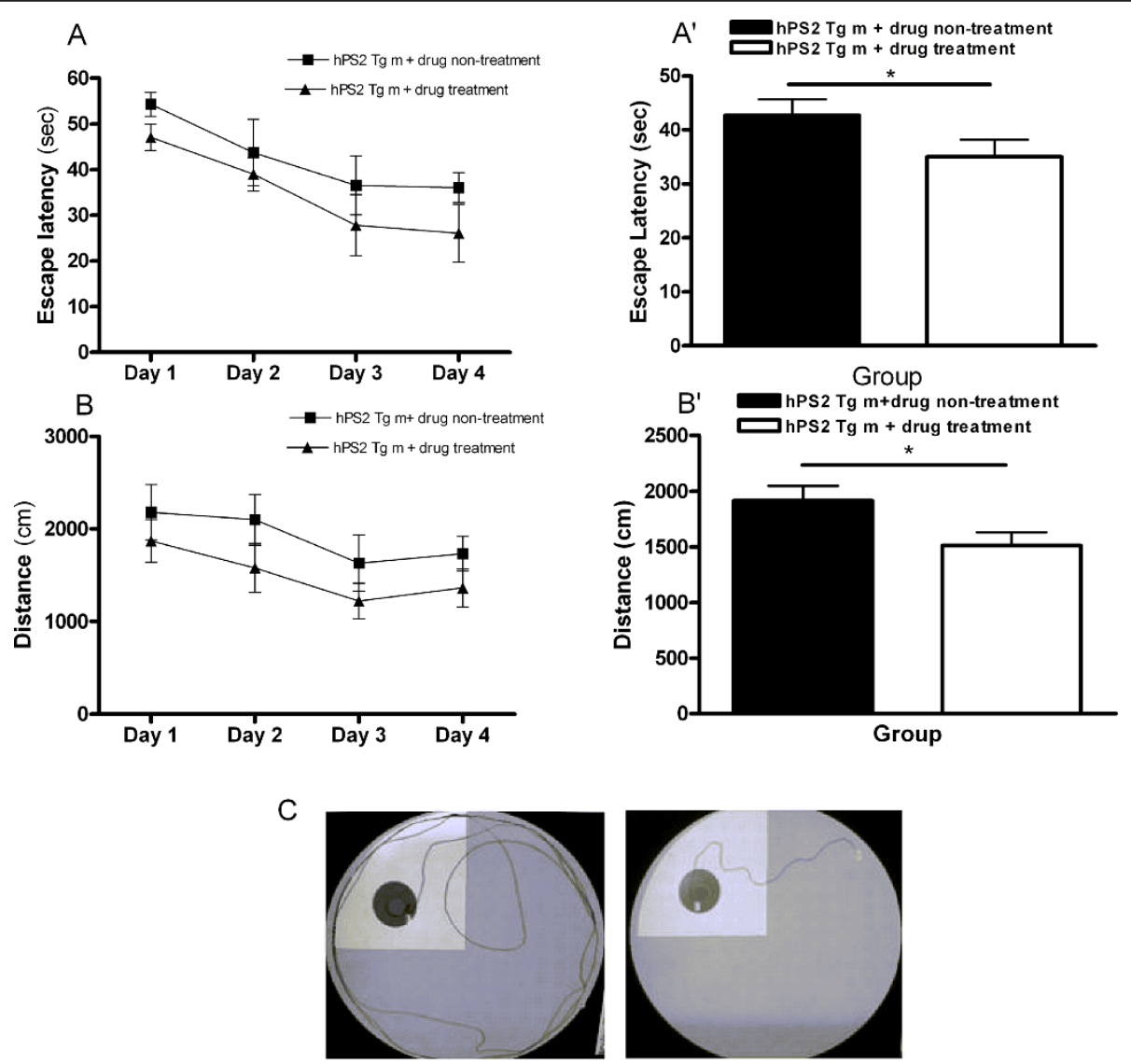

Figure 2 Alteration of escape latency and swimming distance during an acquisition test using the water maze. Four trials per day for 4 consecutive days were conducted and the escape latency ( $\mathbf{A}$ and $\mathbf{A}^{\prime}$ ) and swimming distance (B and $\left.\mathbf{B}^{\prime}\right)$ were measured. Representative images (C) showing the swimming path of mice during the tests. Left: drug non treated- hPS2 transgenic mice and right: drug treated-hPS2 transgenic mice. Data are presented as mean \pm SEM, and comparisons between the two groups were evaluated by the unpaired $t$-test. ${ }^{*} P<0.05$ compared to the drug treated-hPS2 transgenic mice.

transgenic mice showed a significantly reduced escape latency when compared with the hPS2 transgenic mice $(t$-test; $t=1.762, d f=34, p=0.0438)$. As shown in Figure $2 \mathrm{~B}$ and $2 \mathrm{~B}$, the total swimming distance differed significantly among groups $[\mathrm{F}(1,21)=7.70, \mathrm{p}<0.05]$. On days 1-4, the drug treated-hPS2 transgenic mice showed a significantly reduced escape latency when compared with the hPS2 transgenic mice $(t$-test; $\mathrm{t}=$ $2.183, \mathrm{df}=34, \mathrm{p}=0.0180)$. Conversely, there was no significant difference in the average swimming speed among groups on all training days (data not shown).

The performance on the probe trial, which compared the percentage of time spent swimming around the platform on day 5, is illustrated in Figure 3A. There was no significant difference in time spent swimming around the platform among the mice (Figure 3B). The learning and memory retention performance test revealed that the drug treated-hPS2 transgenic mice spent a slightly longer time around the platform than the hPS2 transgenic mice, but this difference was not significant $(t$-test; $\mathrm{t}=0.1253, \mathrm{df}=$
$7, p=0.452)$. These findings indicated that PM012 treatment ameliorated spatial memory impairment in hPS2m mice without affecting locomotive activity.

\section{Safety assessment}

\section{Clinical observations and survival}

The rats from all treatment groups appeared to be healthy at the conclusion of the study period (Table 2). In general, there were no statistically significant changes in body weights (Figure 4). There were no significant differences in food (Figure 5) and water (Figure 6) consumption between the control and treatment groups. In addition, there were no statistically significant differences in food and water consumption, regardless of sex or recovery group (Figure 5 and 6). No abnormal findings were found in the ophthalmic examination (data not shown).

\section{Urinalysis}

Semi-quantitative urinary examinations, such as $\mathrm{pH}$, specific gravity, protein, glucose, urea acid, ketone and 

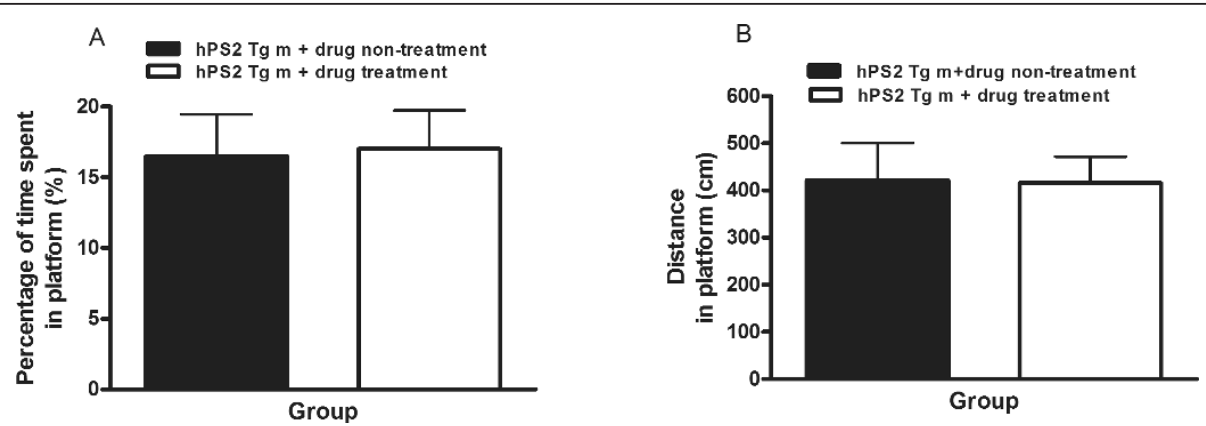

Figure 3 Alteration of time spent and distance around the platform and during the memory retention test in the water maze. Four trials were conducted on the fifth day without the platform and the search latency (A) and distance (B) were measured. Data are presented as mean \pm SEM, and comparisons between the two groups were made using the unpaired $t$-test. ${ }^{*} P<0.05$, compared to the drug treated-hPS2 transgenic mice.

occult blood, did not reveal any relevant changes following acute administration of the PM012 extract (Additional file 1: Table S1). Moreover, PM012 treatment did not cause any significant changes in the presence of urinary sediments (data not shown). In recovery groups, the urine volume in males treated with $2,000 \mathrm{mg} / \mathrm{kg} /$ day was significantly $(\mathrm{P}<0.05)$ higher than that in the vehicle control group.

\section{Hematology}

Hematology data are summarized in Table 3. No statistically significant differences were observed in the hematology parameters, including RBC, PLT, WBC, NEU, LYM, MONO, EOS, BASO, and LUC counts upon PM012 treatment. Similarly, there were no significant changes in clotting time, HDW, Hb, RET, HCT, HGB, $\mathrm{MCV}, \mathrm{RDW}, \mathrm{MCH}, \mathrm{MCHC}$ and MPV values between the control and treated animals (main groups). In recovery groups, the increases in $\mathrm{MCV}, \mathrm{MCH}, \mathrm{HDW}$ and LYM, and the decrease in NEU observed in females treated with $2,000 \mathrm{mg} / \mathrm{kg} /$ day were statistically significant $(\mathrm{P}<0.05)$ compared with the vehicle control group. Serum biochemistry

Serum biochemistry data are summarized in Table 4 . There were no significant changes in the levels of CPK,

Table 2 Abnormal clinical signs and mortality in rats orally treated with PM012

\begin{tabular}{llll}
\hline Sex & Dose $\mathbf{( m g} / \mathbf{k g})$ & \multicolumn{2}{l}{ Observations } \\
\cline { 3 - 4 } & & $\mathbf{0 - 4}$ Weeks & $\mathbf{0 - 2 6}$ Weeks \\
\hline Male & 0 & Appears normal & Appears normal \\
& 500 & Appears normal & Appears normal \\
& 1000 & Appears normal & Appears normal \\
& 2000 & Appears normal & Appears normal \\
Female & 0 & Appears normal & Appears normal \\
& 500 & Appears normal & Appears normal \\
& 1000 & Appears normal & Appears normal \\
& 2000 & Appears normal & Appears normal \\
\hline
\end{tabular}

GLU, CHO, TG, A/G, BUN, CRE or IP. Female mice treated with 2,000 mg/kg/day PM012 extract exhibited significantly increased PRO. No statistically significant differences in serum electrolytes such as $\mathrm{K}^{+}$or $\mathrm{Cl}^{-}$were noted. Male mice treated with $1,000 \mathrm{mg} / \mathrm{kg} /$ day PM012 extract exhibited significantly decreased $\mathrm{Ca}^{2+}$ (main groups). Moreover, female mice treated with $1,000 \mathrm{mg} /$ kg/day PM012 extract exhibited significantly decreased $\mathrm{Na}^{+}$(main groups). The effects of PM012 on liver function parameters such as AST, ALT, ALP, and BIL in serum were also investigated. Female mice treated with 500 and 2,000 mg/kg/day PM012 extract exhibited significantly increased ALB. The $1,000 \mathrm{mg} / \mathrm{kg} /$ day exposure groups and recovery groups, however, did not exhibit significant changes in serum AST, ALT, ALP or BIL.

\section{Organ weights}

Organ weight data are summarized in Table 5. Thymus weight showed a dose-related increasing trend in the main and recovery female groups and a significant increase $(P<0.01)$ was identified in the $2,000 \mathrm{mg} / \mathrm{kg} /$ day recovery group. No statistically significantly differences were observed in males

\section{Histopathology}

Histopathological examinations are an important aspect of safety assessments. A macroscopic examination of vital organs found no abnormalities. Histological evaluation of the adrenal gland, pituitary gland, prostate gland, kidney, liver, spleen, lung, heart, thymus, thyroid gland, mesenteric and harderian glands did not reveal any pathological changes in the highest dose group (data not shown).

\section{Discussion}

Natural products have long been used in traditional medicine to treat various diseases. Extracts prepared from medicinal plants and other natural sources contain a variety of molecules with potent biological activities. However, it is often difficult to analyze the biological 


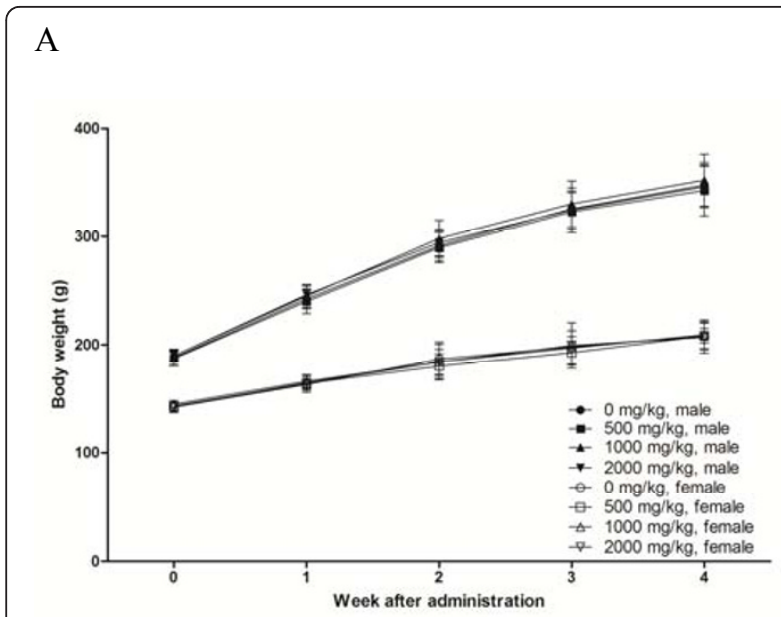

B

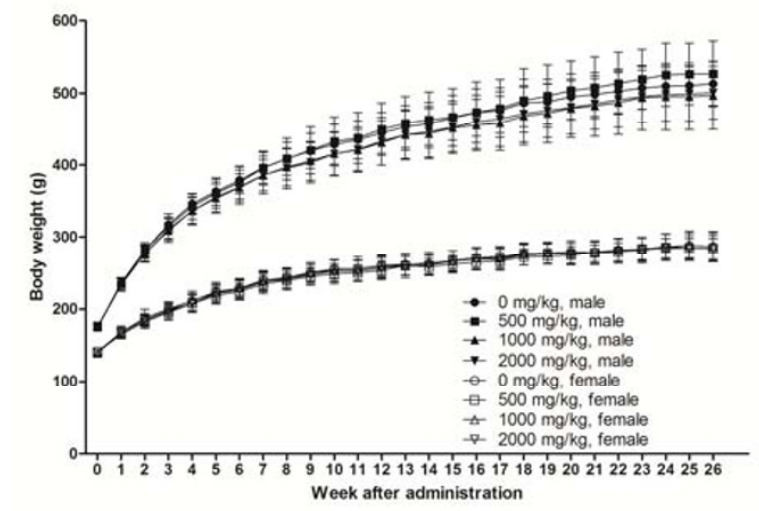

$\mathrm{C}$

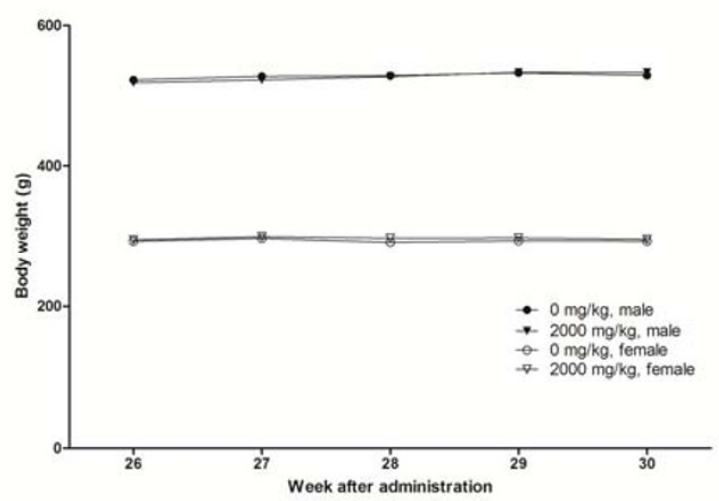

Figure 4 Mean body weight of male and female rats dosed with PM012. Each data point represents the mean body weight of groups of ten or fifteen animals. A) main group receiving 4 weeks of treatment, B) main group receiving 26 weeks of treatment and C) 4 weeks recovery group. Statistical analysis of the data (Dunnett's test) revealed no significance differences between groups.

\section{A}

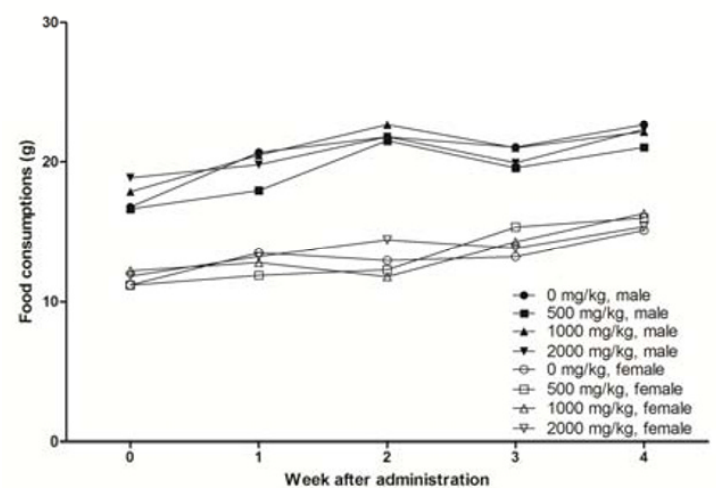

B

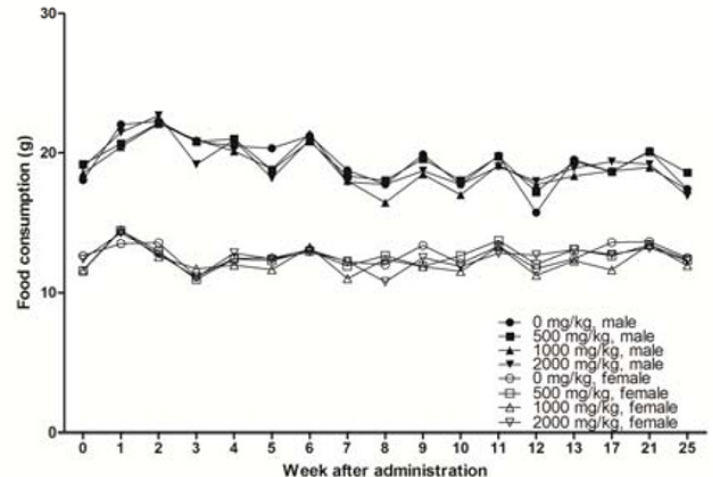

C

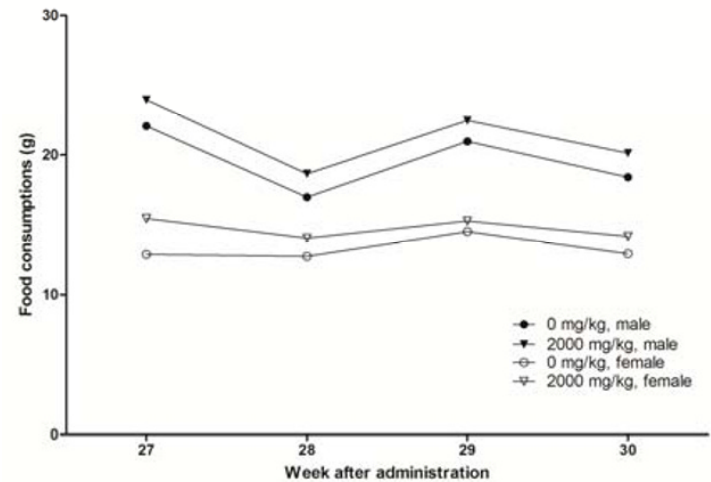

Figure 5 Mean food consumption by male and female rats treated with PM012. Each data point represents the mean food consumption of groups of ten or fifteen animals. A) main group receiving 4 weeks of treatment, B) main group receiving 26 weeks of treatment and C) 4 weeks recovery group. Statistical analysis of the data (Dunnett's test) revealed no significance differences between groups. 


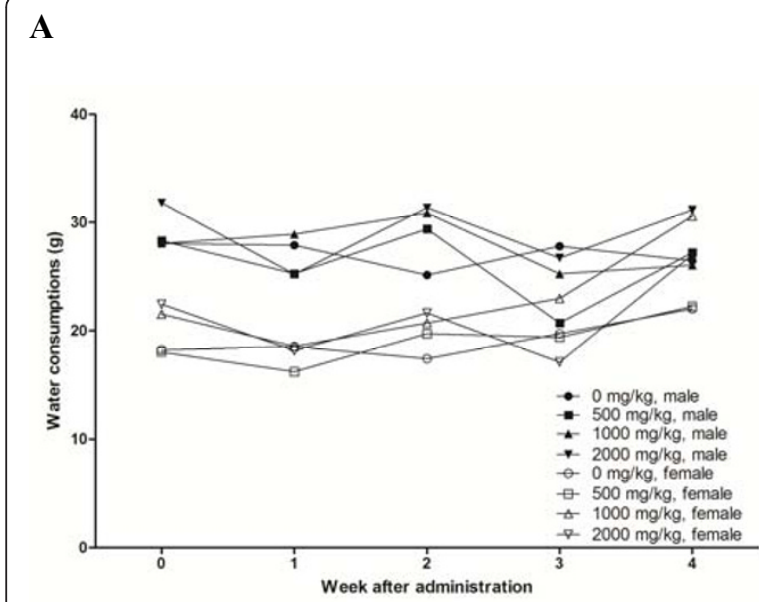

B

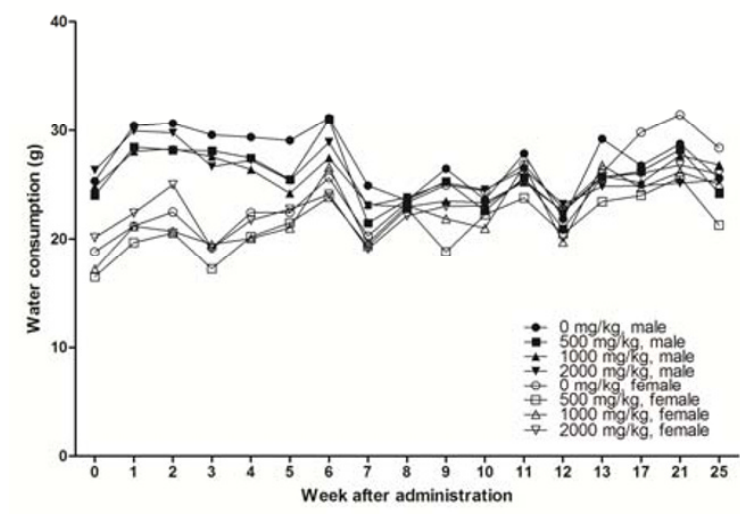

C

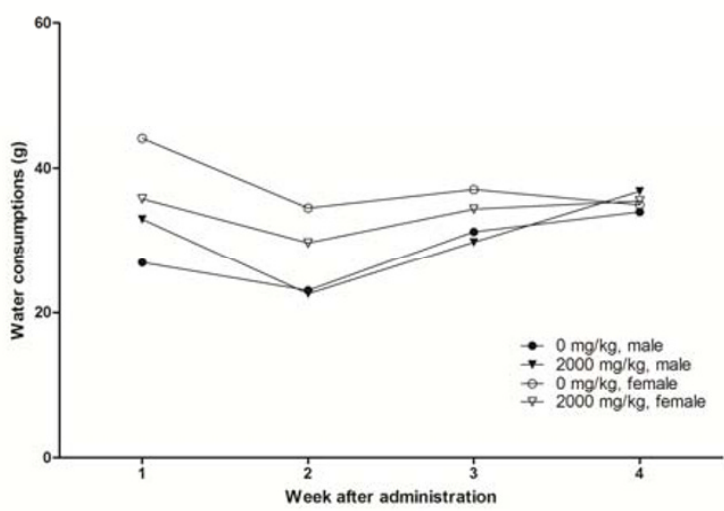

Figure 6 Mean water consumption by male and female rats treated with PM012. Each data point represents the mean water consumption of groups of ten or fifteen animals. A) main group receiving 4 weeks of treatment, B) main group receiving 26 weeks of treatment and C) 4 weeks recovery group. Statistical analysis of the data (Dunnett's test) revealed no significance differences between groups. activities of these extracts because of their complex nature and the possible synergistic effects of their components. Recently, the raw materials of such products have been used to develop new drugs $[1,25,26]$.

Many studies have reported the pharmacological efficacy of PM012. PM012 was shown to have potent protection effects against ibotenic acid-induced cell damage and cognitive deficits in a previous study [27]. In addition, PM012 treatment accelerated the speed of information processing and enhanced cognitive abilities in normal subjects [28]. PM012 may repair cognitive impairment induced by dementia through an increase of acetylcholine synthesis in combination with the other advantageous effects mentioned above, thus helping to alleviate the symptoms of dementia patients [15,27,28].

The components of PM012 have been shown to have various effects when used individually. Mountain cortex radicis, a component of PM012, decreased ROS generation and cytotoxicity in hydrogen peroxide-stimulated neuronal cells through increasing the expression of the genes heme oxygenase and COMT, which play a major role in regulating ROS production [29]. Rehmanniae Radix, another component of PM012, improved learning and memory in monosodium glutamate-treated rats through anti-oxidation and increased the expression of hippocampal c-fos and NGF and intelligence in humans [2,3]. It has been reported that Lycii Fructus and Corni fructus, additional components of PM012, have strong anti-oxidative effects $[4,30]$. Furthermore, Lycii Fructus [31], Corni fructus [32], Rehmannia radix [21], Discoreae radix [33], and Mountain cortex radicis [34], have all shown anti-inflammatory effects. However, to date, there is no information on any aspects, such as oral toxicity, of the safety of any of these components or PM012. Therefore, we investigated and here report the safety of repeated oral administration as determined by a toxicity experiment conducted with a crude extract of PM012 using male and female SD rats.

The present study was performed to evaluate the efficacy of PM012 in hPS2m transgenic mice and the toxicity of PM012 in SD rats after 4- or 26-week repeated oral administrations and to identify the no observed adverse effect level (NOAEL), target organs and the recovery potential during the 4-week recovery study. The Morris water maze task was used to test the effect of PM012 on the relative spatial learning capability and reference memory in hPS2m mice to determine whether PM012 can protect against memory impairment. The Morris water maze spatial learning task has been used in the validation of rodent models for neurocognitive disorders and for the evaluation of possible neurocognitive treatments. In the current study, the latency to find the platform in acquisition trials by the PM012-treated 
Table 3 Hematological values in rats orally treated with PM012

\begin{tabular}{|c|c|c|c|c|c|c|c|c|c|c|c|c|}
\hline \multirow{3}{*}{ Parameter } & \multirow{3}{*}{ Unit } & \multirow{3}{*}{ Sex } & \multicolumn{10}{|c|}{ Hematological values } \\
\hline & & & \multicolumn{3}{|c|}{$0 \mathrm{mg} / \mathrm{kg}$} & \multicolumn{2}{|c|}{$500 \mathrm{mg} / \mathrm{kg}$} & \multicolumn{2}{|c|}{$1000 \mathrm{mg} / \mathrm{kg}$} & \multicolumn{3}{|c|}{$2000 \mathrm{mg} / \mathrm{kg}$} \\
\hline & & & 4 Weeks & 26 Weeks & Recovery & 4 Weeks & 26 Weeks & 4 Weeks & 26 Weeks & 4 Weeks & 26 Weeks & Recovery \\
\hline \multirow[t]{2}{*}{ WBC } & $\begin{array}{c}10^{3} / \\
\mu \mathrm{L}\end{array}$ & Male & $\begin{array}{c}11.12 \pm \\
2.81\end{array}$ & $\begin{array}{c}8.37 \pm \\
1.35\end{array}$ & $\begin{array}{c}7.63 \pm \\
2.04\end{array}$ & $\begin{array}{c}14.14 \pm \\
2.29\end{array}$ & $9.47 \pm 2.14$ & $\begin{array}{c}11.17 \pm \\
3.22\end{array}$ & $\begin{array}{c}8.35 \pm \\
2.56\end{array}$ & $\begin{array}{c}10.88 \pm \\
3.18\end{array}$ & $\begin{array}{c}8.99 \pm \\
1.97\end{array}$ & $\begin{array}{c}7.70 \pm \\
1.07\end{array}$ \\
\hline & & Female & $\begin{array}{c}6.78 \pm \\
0.78\end{array}$ & $\begin{array}{c}4.73 \pm \\
0.92\end{array}$ & $\begin{array}{c}5.82 \pm \\
1.86\end{array}$ & $\begin{array}{l}7.61 \pm \\
0.75\end{array}$ & $4.20 \pm 0.95$ & $\begin{array}{c}9.15 \pm \\
3.92\end{array}$ & $\begin{array}{c}4.83 \pm \\
1.50\end{array}$ & $\begin{array}{c}8.89 \pm \\
2.60\end{array}$ & $\begin{array}{c}4.93 \pm \\
1.06\end{array}$ & $\begin{array}{c}5.65 \pm \\
1.43\end{array}$ \\
\hline \multirow[t]{2}{*}{$\mathrm{RBC}$} & $\begin{array}{l}10^{6} / \\
\mu \mathrm{L}\end{array}$ & Male & $\begin{array}{c}8.03 \pm \\
0.17\end{array}$ & $\begin{array}{c}9.04 \pm \\
0.28\end{array}$ & $\begin{array}{c}8.72 \pm \\
0.38\end{array}$ & $\begin{array}{c}8.12 \pm \\
0.24\end{array}$ & $9.12 \pm 0.32$ & $\begin{array}{c}8.11 \pm \\
0.20\end{array}$ & $\begin{array}{c}8.86 \pm \\
0.19\end{array}$ & $\begin{array}{c}8.24 \pm \\
0.06\end{array}$ & $\begin{array}{c}8.89 \pm \\
0.27\end{array}$ & $\begin{array}{c}8.65 \pm \\
0.26\end{array}$ \\
\hline & & Female & $\begin{array}{c}7.99 \pm \\
0.20\end{array}$ & $\begin{array}{c}8.00 \pm \\
0.25\end{array}$ & $\begin{array}{c}7.68 \pm \\
0.30\end{array}$ & $\begin{array}{c}7.72 \pm \\
0.43\end{array}$ & $8.09 \pm 0.27$ & $\begin{array}{c}7.69 \pm \\
0.29\end{array}$ & $\begin{array}{c}8.12 \pm \\
0.52\end{array}$ & $\begin{array}{c}7.76 \pm \\
0.18\end{array}$ & $\begin{array}{c}7.96 \pm \\
0.18\end{array}$ & $\begin{array}{c}7.61 \pm \\
0.22\end{array}$ \\
\hline \multirow[t]{2}{*}{$H G B$} & $\mathrm{~g} / \mathrm{dL}$ & Male & $\begin{array}{c}15.38 \pm \\
0.53\end{array}$ & $15.5 \pm 0.3$ & $15.0 \pm 0.8$ & $\begin{array}{c}15.40 \pm \\
0.26\end{array}$ & $15.8 \pm 0.5$ & $\begin{array}{c}15.42 \pm \\
0.50\end{array}$ & $15.2 \pm 0.4$ & $\begin{array}{c}15.44 \pm \\
0.33\end{array}$ & $15.2 \pm 0.3$ & $14.9 \pm 0.5$ \\
\hline & & Female & $\begin{array}{c}14.86 \pm \\
0.41\end{array}$ & $14.5 \pm 0.5$ & $13.7 \pm 0.5$ & $\begin{array}{c}14.54 \pm \\
0.52\end{array}$ & $14.5 \pm 0.4$ & $\begin{array}{c}14.50 \pm \\
0.69\end{array}$ & $14.6 \pm 0.7$ & $\begin{array}{c}14.88 \pm \\
0.41\end{array}$ & $14.4 \pm 0.5$ & $14.1 \pm 0.4$ \\
\hline \multirow[t]{2}{*}{$\mathrm{HCT}$} & $\%$ & Male & $\begin{array}{c}43.62 \pm \\
1.40\end{array}$ & $46.2 \pm 1.0$ & $45.2 \pm 2.4$ & $\begin{array}{c}43.62 \pm \\
0.87\end{array}$ & $46.9 \pm 1.3$ & $\begin{array}{c}43.76 \pm \\
1.24\end{array}$ & $45.2 \pm 1.4$ & $\begin{array}{c}43.82 \pm \\
1.04\end{array}$ & $45.1 \pm 0.9$ & $44.3 \pm 1.1$ \\
\hline & & Female & $\begin{array}{c}42.08 \pm \\
0.88\end{array}$ & $42.5 \pm 1.4$ & $40.9 \pm 1.4$ & $\begin{array}{c}41.50 \pm \\
1.52\end{array}$ & $42.8 \pm 1.4$ & $\begin{array}{c}40.94 \pm \\
1.30\end{array}$ & $43.2 \pm 1.8$ & $\begin{array}{c}41.74 \pm \\
1.06\end{array}$ & $42.4 \pm 1.2$ & $41.5 \pm 1.3$ \\
\hline \multirow[t]{2}{*}{ MCV } & $\mathrm{fL}$ & Male & $\begin{array}{c}54.28 \pm \\
1.10\end{array}$ & $51.1 \pm 1.5$ & $51.9 \pm 2.5$ & $\begin{array}{c}53.72 \pm \\
1.45\end{array}$ & $51.5 \pm 1.0$ & $\begin{array}{c}54.00 \pm \\
1.22\end{array}$ & $51.1 \pm 1.1$ & $\begin{array}{c}53.14 \pm \\
1.48\end{array}$ & $50.8 \pm 1.5$ & $51.2 \pm 0.9$ \\
\hline & & Female & $\begin{array}{c}52.68 \pm \\
0.31\end{array}$ & $53.1 \pm 0.7$ & $53.2 \pm 1.0$ & $\begin{array}{c}53.82 \pm \\
1.25\end{array}$ & $52.9 \pm 1.8$ & $\begin{array}{c}53.28 \pm \\
0.75\end{array}$ & $53.3 \pm 2.3$ & $\begin{array}{c}53.84 \pm \\
1.00\end{array}$ & $53.3 \pm 1.2$ & $54.7 \pm 0.5$ \\
\hline \multirow[t]{2}{*}{$\mathrm{MCH}$} & $\mathrm{pg}$ & Male & $\begin{array}{c}19.14 \pm \\
0.43\end{array}$ & $17.2 \pm 0.5$ & $17.3 \pm 0.8$ & $\begin{array}{c}19.00 \pm \\
0.47\end{array}$ & $17.4 \pm 0.4$ & $\begin{array}{c}19.06 \pm \\
0.30\end{array}$ & $17.1 \pm 0.3$ & $\begin{array}{c}18.74 \pm \\
0.44\end{array}$ & $17.1 \pm 0.4$ & $17.2 \pm 0.3$ \\
\hline & & Female & $\begin{array}{c}18.56 \pm \\
0.19\end{array}$ & $18.1 \pm 0.3$ & $17.9 \pm 0.2$ & $\begin{array}{c}18.88 \pm \\
0.43\end{array}$ & $17.9 \pm 0.5$ & $\begin{array}{c}18.88 \pm \\
0.40\end{array}$ & $18.1 \pm 0.7$ & $\begin{array}{c}19.18 \pm \\
0.30\end{array}$ & $18.1 \pm 0.5$ & $18.4 \pm 0.2$ \\
\hline \multirow[t]{2}{*}{$\mathrm{MCHC}$} & $\mathrm{g} / \mathrm{dL}$ & Male & $\begin{array}{c}35.22 \pm \\
0.18\end{array}$ & $33.6 \pm 0.4$ & $33.3 \pm 0.3$ & $\begin{array}{c}35.32 \pm \\
0.57\end{array}$ & $33.7 \pm 0.4$ & $\begin{array}{c}35.28 \pm \\
0.41\end{array}$ & $33.6 \pm 0.4$ & $\begin{array}{c}35.28 \pm \\
0.47\end{array}$ & $33.7 \pm 0.3$ & $33.7 \pm 0.4$ \\
\hline & & Female & $\begin{array}{c}35.24 \pm \\
0.48\end{array}$ & $34.1 \pm 0.5$ & $33.7 \pm 0.2$ & $\begin{array}{c}35.06 \pm \\
0.29\end{array}$ & $33.9 \pm 0.6$ & $\begin{array}{c}35.38 \pm \\
0.90\end{array}$ & $33.9 \pm 0.5$ & $\begin{array}{c}35.58 \pm \\
0.26\end{array}$ & $34.0 \pm 0.4$ & $33.8 \pm 0.2$ \\
\hline \multirow[t]{2}{*}{ RDW } & $\%$ & Male & $\begin{array}{c}15.34 \pm \\
0.47\end{array}$ & $12.3 \pm 0.5$ & $12.7 \pm 0.6$ & $\begin{array}{c}15.30 \pm \\
1.12\end{array}$ & $12.4 \pm 0.5$ & $\begin{array}{c}15.52 \pm \\
0.40\end{array}$ & $12.1 \pm 0.4$ & $\begin{array}{c}15.24 \pm \\
0.36\end{array}$ & $12.2 \pm 0.3$ & $12.5 \pm 0.7$ \\
\hline & & Female & $\begin{array}{c}14.84 \pm \\
0.38\end{array}$ & $11.1 \pm 0.4$ & $10.5 \pm 0.4$ & $\begin{array}{c}13.96 \pm \\
0.88\end{array}$ & $11.1 \pm 0.5$ & $\begin{array}{c}14.58 \pm \\
0.70\end{array}$ & $11.2 \pm 0.5$ & $\begin{array}{c}14.18 \pm \\
0.33\end{array}$ & $11.0 \pm 0.3$ & $11.0 \pm 0.5$ \\
\hline \multirow[t]{2}{*}{ HDW } & $\mathrm{g} / \mathrm{dL}$ & Male & $N D^{a)}$ & $\begin{array}{c}2.60 \pm \\
0.14\end{array}$ & $\begin{array}{c}2.73 \pm \\
0.21\end{array}$ & $N D^{a)}$ & $2.68 \pm 0.13$ & $N D^{a)}$ & $\begin{array}{c}2.52 \pm \\
0.18\end{array}$ & $N D^{a)}$ & $\begin{array}{c}2.58 \pm \\
0.14\end{array}$ & $\begin{array}{c}2.53 \pm \\
0.27\end{array}$ \\
\hline & & Female & $N D^{a)}$ & $\begin{array}{c}2.43 \pm \\
0.20\end{array}$ & $\begin{array}{c}2.20 \pm \\
0.11\end{array}$ & $N D^{a)}$ & $2.29 \pm 0.18$ & $N D^{a)}$ & $\begin{array}{c}2.39 \pm \\
0.24\end{array}$ & $N D^{a)}$ & $\begin{array}{c}2.36 \pm \\
0.20\end{array}$ & $\begin{array}{c}2.52 \pm \\
0.23\end{array}$ \\
\hline \multirow[t]{2}{*}{ PLT } & $\begin{array}{l}10^{3} / \\
\mu \mathrm{L}\end{array}$ & Male & $\begin{array}{c}945.2 \pm \\
81.9\end{array}$ & $\begin{array}{c}993.3 \pm \\
82.7\end{array}$ & $\begin{array}{c}10.54 \pm \\
109.3\end{array}$ & $\begin{array}{c}935.2 \pm \\
37.8\end{array}$ & $\begin{array}{c}1015.1 \pm \\
107.4\end{array}$ & $\begin{array}{c}869.6 \pm \\
72.2\end{array}$ & $\begin{array}{c}992.2 \pm \\
66.3\end{array}$ & $\begin{array}{l}930.4 \pm \\
72.1\end{array}$ & $\begin{array}{c}1024.1 \pm \\
97.6\end{array}$ & $\begin{array}{c}10.84 .4 \pm \\
77.0\end{array}$ \\
\hline & & Female & $\begin{array}{c}997.0 \pm \\
72.9\end{array}$ & $\begin{array}{c}1016.5 \pm \\
90.2\end{array}$ & $\begin{array}{c}1013.2 \pm \\
62.5\end{array}$ & $\begin{array}{c}975.0 \pm \\
43.6\end{array}$ & $\begin{array}{c}1017.7 \pm \\
69.6\end{array}$ & $\begin{array}{c}997.8 \pm \\
99.9\end{array}$ & $\begin{array}{c}912.4 \pm \\
264.7\end{array}$ & $\begin{array}{c}985.6 \pm \\
74.1\end{array}$ & $\begin{array}{c}997.3 \pm \\
91.4\end{array}$ & $\begin{array}{c}1019.8 \pm \\
79.7\end{array}$ \\
\hline \multirow[t]{2}{*}{ MPV } & $\mathrm{fL}$ & Male & $\begin{array}{c}5.83 \pm \\
0.49\end{array}$ & $\begin{array}{c}5.92 \pm \\
0.27\end{array}$ & $\begin{array}{c}5.94 \pm \\
0.29\end{array}$ & $\begin{array}{c}5.67 \pm \\
0.22\end{array}$ & $5.94 \pm 0.20$ & $\begin{array}{c}5.91 \pm \\
0.29\end{array}$ & $\begin{array}{c}5.82 \pm \\
0.17\end{array}$ & $\begin{array}{c}5.81 \pm \\
0.20\end{array}$ & $\begin{array}{c}5.78 \pm \\
0.15\end{array}$ & $\begin{array}{c}5.98 \pm \\
0.37\end{array}$ \\
\hline & & Female & $\begin{array}{c}5.90 \pm \\
0.33\end{array}$ & $\begin{array}{c}6.02 \pm \\
0.13\end{array}$ & $\begin{array}{l}5.88 \pm \\
0.13\end{array}$ & $\begin{array}{c}5.90 \pm \\
0.09\end{array}$ & $6.16 \pm 0.25$ & $\begin{array}{c}5.67 \pm \\
0.19\end{array}$ & $\begin{array}{c}7.12 \pm \\
2.44\end{array}$ & $\begin{array}{l}5.73 \pm \\
0.15\end{array}$ & $\begin{array}{l}6.36 \pm \\
0.84\end{array}$ & $\begin{array}{c}5.90 \pm \\
0.19\end{array}$ \\
\hline \multirow[t]{2}{*}{ RET } & $\%$ & Male & $\begin{array}{c}2.2 \pm \\
0.84\end{array}$ & $\begin{array}{c}2.22 \pm \\
0.22\end{array}$ & $\begin{array}{c}2.31 \pm \\
0.28\end{array}$ & $\begin{array}{l}1.8 \pm \\
0.84\end{array}$ & $2.20 \pm 0.20$ & $\begin{array}{c}2.0 \pm \\
1.41\end{array}$ & $\begin{array}{c}2.10 \pm \\
0.27\end{array}$ & $\begin{array}{c}2.4 \pm \\
1.14\end{array}$ & $\begin{array}{c}2.15 \pm \\
0.26\end{array}$ & $\begin{array}{c}2.32 \pm \\
0.30\end{array}$ \\
\hline & & Female & $\begin{array}{c}3.4 \pm \\
1.82\end{array}$ & $\begin{array}{c}2.39 \pm \\
0.33\end{array}$ & $\begin{array}{c}1.81 \pm \\
0.51\end{array}$ & $\begin{array}{c}3.8 \pm \\
1.30\end{array}$ & $2.47 \pm 0.36$ & $\begin{array}{c}3.2 \pm \\
1.48\end{array}$ & $\begin{array}{c}2.30 \pm \\
0.60\end{array}$ & $\begin{array}{c}2.2 \pm \\
1.64\end{array}$ & $\begin{array}{c}2.26 \pm \\
0.28\end{array}$ & $\begin{array}{c}2.36 \pm \\
0.27\end{array}$ \\
\hline \multirow[t]{2}{*}{ NEU } & $\%$ & Male & $\begin{array}{c}12.75 \pm \\
3.77\end{array}$ & $\begin{array}{c}26.6 \pm \\
10.7\end{array}$ & $16.2 \pm 4.5$ & $\begin{array}{l}9.81 \pm \\
2.15\end{array}$ & $29.8 \pm 8.9$ & $\begin{array}{c}14.30 \pm \\
4.91\end{array}$ & $\begin{array}{c}25.2 \pm \\
11.0\end{array}$ & $\begin{array}{c}13.06 \pm \\
6.29\end{array}$ & $23.5 \pm 7.1$ & $17.5 \pm 6.0$ \\
\hline & & Female & $\begin{array}{c}10.25 \pm \\
1.99\end{array}$ & $16.8 \pm 4.5$ & $\begin{array}{c}31.3 \pm \\
13.9\end{array}$ & $\begin{array}{l}9.06 \pm \\
2.03\end{array}$ & $16.6 \pm 2.3$ & $\begin{array}{c}9.87 \pm \\
4.91\end{array}$ & $17.1 \pm 5.3$ & $\begin{array}{c}9.46 \pm \\
2.87\end{array}$ & $16.3 \pm 3.6$ & $15.4 \pm 3.7$ \\
\hline \multirow[t]{2}{*}{ LYM } & $\%$ & Male & $\begin{array}{c}79.76 \pm \\
5.96\end{array}$ & $\begin{array}{c}68.2 \pm \\
10.7\end{array}$ & $77.2 \pm 5.0$ & $\begin{array}{c}84.80 \pm \\
2.56\end{array}$ & $64.6 \pm 8.6$ & $\begin{array}{c}77.52 \pm \\
5.76\end{array}$ & $\begin{array}{c}69.0 \pm \\
10.5\end{array}$ & $\begin{array}{c}79.90 \pm \\
7.43\end{array}$ & $70.6 \pm 6.5$ & $74.7 \pm 7.8$ \\
\hline & & Female & $\begin{array}{c}82.46 \pm \\
3.14\end{array}$ & $78.0 \pm 4.5$ & $\begin{array}{c}61.9 \pm \\
12.5\end{array}$ & $\begin{array}{c}85.10 \pm \\
2.67\end{array}$ & $77.6 \pm 2.3$ & $\begin{array}{c}83.96 \pm \\
5.54\end{array}$ & $76.4 \pm 6.5$ & $\begin{array}{c}83.84 \pm \\
2.46\end{array}$ & $77.8 \pm 4.0$ & $77.8 \pm 4.1$ \\
\hline
\end{tabular}


Table 3 Hematological values in rats orally treated with PM012 (Continued)

\begin{tabular}{|c|c|c|c|c|c|c|c|c|c|c|c|c|}
\hline \multirow[t]{2}{*}{ MONO } & $\%$ & Male & $\begin{array}{c}4.40 \pm \\
1.85\end{array}$ & $\begin{array}{c}3.05 \pm \\
0.36\end{array}$ & $\begin{array}{c}4.12 \pm \\
1.52\end{array}$ & $\begin{array}{c}2.77 \pm \\
1.01\end{array}$ & $3.57 \pm 1.09$ & $\begin{array}{c}4.41 \pm \\
1.39\end{array}$ & $\begin{array}{c}3.52 \pm \\
0.96\end{array}$ & $\begin{array}{c}3.66 \pm \\
0.97\end{array}$ & $\begin{array}{c}3.74 \pm \\
0.90\end{array}$ & $\begin{array}{c}5.36 \pm \\
1.81\end{array}$ \\
\hline & & Female & $\begin{array}{c}3.75 \pm \\
1.08\end{array}$ & $\begin{array}{c}2.77 \pm \\
0.79\end{array}$ & $\begin{array}{c}4.24 \pm \\
1.05\end{array}$ & $\begin{array}{c}2.84 \pm \\
0.80\end{array}$ & $3.01 \pm 0.65$ & $\begin{array}{c}2.90 \pm \\
0.70\end{array}$ & $\begin{array}{c}3.64 \pm \\
0.98\end{array}$ & $\begin{array}{c}3.33 \pm \\
0.50\end{array}$ & $\begin{array}{c}3.68 \pm \\
0.94\end{array}$ & $\begin{array}{c}3.92 \pm \\
0.33\end{array}$ \\
\hline \multirow[t]{2}{*}{ EOS } & $\%$ & Male & $\begin{array}{c}0.64 \pm \\
0.27\end{array}$ & $\begin{array}{c}1.47 \pm \\
0.36\end{array}$ & $\begin{array}{c}1.52 \pm \\
0.59\end{array}$ & $\begin{array}{c}0.53 \pm \\
0.32\end{array}$ & $1.29 \pm 0.49$ & $\begin{array}{c}0.64 \pm \\
0.10\end{array}$ & $\begin{array}{c}1.62 \pm \\
0.62\end{array}$ & $\begin{array}{c}0.83 \pm \\
0.39\end{array}$ & $\begin{array}{c}1.40 \pm \\
0.75\end{array}$ & $\begin{array}{c}1.08 \pm \\
0.42\end{array}$ \\
\hline & & Female & $\begin{array}{c}0.95 \pm \\
0.64\end{array}$ & $\begin{array}{c}1.67 \pm \\
0.47\end{array}$ & $\begin{array}{c}1.74 \pm \\
0.58\end{array}$ & $\begin{array}{c}0.83 \pm \\
0.33\end{array}$ & $2.04 \pm 0.87$ & $\begin{array}{c}0.97 \pm \\
0.52\end{array}$ & $\begin{array}{c}1.79 \pm \\
0.58\end{array}$ & $\begin{array}{c}0.88 \pm \\
0.29\end{array}$ & $\begin{array}{c}1.36 \pm \\
0.37\end{array}$ & $\begin{array}{c}2.04 \pm \\
0.42\end{array}$ \\
\hline \multirow[t]{2}{*}{ BASO } & $\%$ & Male & $\begin{array}{c}2.43 \pm \\
0.75\end{array}$ & $\begin{array}{c}0.12 \pm \\
0.06\end{array}$ & $\begin{array}{c}0.16 \pm \\
0.05\end{array}$ & $\begin{array}{c}2.10 \pm \\
0.60\end{array}$ & $0.15 \pm 0.05$ & $\begin{array}{c}3.11 \pm \\
0.44\end{array}$ & $\begin{array}{c}0.17 \pm \\
0.08\end{array}$ & $\begin{array}{c}2.56 \pm \\
0.47\end{array}$ & $\begin{array}{c}0.17 \pm \\
0.07\end{array}$ & $\begin{array}{c}0.22 \pm \\
0.04\end{array}$ \\
\hline & & Female & $\begin{array}{c}2.58 \pm \\
0.61\end{array}$ & $\begin{array}{c}0.12 \pm \\
0.06\end{array}$ & $\begin{array}{c}0.10 \pm \\
0.00\end{array}$ & $\begin{array}{c}2.18 \pm \\
0.45\end{array}$ & $0.18 \pm 0.15$ & $\begin{array}{c}2.31 \pm \\
0.45\end{array}$ & $\begin{array}{c}0.16 \pm \\
0.08\end{array}$ & $\begin{array}{c}2.50 \pm \\
0.56\end{array}$ & $\begin{array}{c}0.12 \pm \\
0.04\end{array}$ & $\begin{array}{c}0.12 \pm \\
0.04\end{array}$ \\
\hline \multirow[t]{2}{*}{ LUC } & $\%$ & Male & $N D^{a)}$ & $\begin{array}{c}0.57 \pm \\
0.22\end{array}$ & $\begin{array}{c}0.78 \pm \\
0.26\end{array}$ & $N D^{a)}$ & $0.63 \pm 0.33$ & $N D^{a)}$ & $\begin{array}{l}0.58 \pm \\
0.15\end{array}$ & $N D^{a)}$ & $\begin{array}{l}0.61 \pm \\
0.23\end{array}$ & $\begin{array}{c}1.14 \pm \\
0.92\end{array}$ \\
\hline & & Female & $N D^{a)}$ & $\begin{array}{c}0.62 \pm \\
0.21\end{array}$ & $\begin{array}{c}0.74 \pm \\
0.30\end{array}$ & $N D^{a)}$ & $0.65 \pm 0.35$ & $N D^{a)}$ & $\begin{array}{c}0.86 \pm \\
0.31\end{array}$ & $N D^{a)}$ & $\begin{array}{c}0.72 \pm \\
0.35\end{array}$ & $\begin{array}{c}0.74 \pm \\
0.28\end{array}$ \\
\hline
\end{tabular}

* WBC: white blood cell, RBC: red blood cell, HGB: hemoglobin concentration, HCT: hematocrit, MCV: mean corpuscular volume, MCH: mean corpuscular hemoglobin, MCHC: mean corpuscular hemoglobin concentration, RDW: Red cell distribution width, PLT: Platelet, MPV: Mean platelet volume, RET: Reticulocyte, NEU: Neutrophil, LYM: Lymphocyte, MONO: Monocyte, EOS: Eosinophil, BASO: Basophil. Values are mean \pm SD ( $n=5$ (4 weeks) or 10 (26 weks)/sex/dose). P < 0.05 compare with normal group. ${ }^{\text {b) }} \mathrm{ND}$, not determined.

group was significantly decreased compared to the untreated group. The PM012-treated group also spent a greater proportion of the probe trial searching in the training quadrant, demonstrating that PM012 attenuated the hPS2 mutation-induced learning and memory deficits. Weight loss is a frequent condition of $\mathrm{AD}$, occurring in about $30 \%-40 \%$ of all $\mathrm{AD}$ patients $[35,36]$. Body weight was significantly increased in the PM012-treated group, suggesting possible beneficial effects of PM012 on $\mathrm{AD}$ progression. In terms of safety, no mortality was observed and no abnormal changes were observed in the body weight, food and water consumption, ophthalmic examination, urinalysis and blood clotting time test.

In the clinical examination of the rats used in the safety assessment, some rats presented with anomalous pathologies but no significant differences were found in relation to treatment with PM012. A mass observed in one female treated with $1,000 \mathrm{mg} / \mathrm{kg} /$ day was identified as a fibroadenoma, a benign tumor derived from mammary epithelium and connective tissue. It is a spontaneous tumor that is commonly observed in rats [37-39]. In the hematological and serum biochemistry tests, all changes observed in the female recovery group and main groups of both sexes were within normal levels and no significant changes were found in the related test parameters. In terms of organ weights, the increases of the absolute and relative weights of the thymus observed in the female $2,000 \mathrm{mg} / \mathrm{kg} /$ day recovery group were similar to those in the 4-week repeated dose toxicity study, and a dose-related increasing trend was observed in the female main groups. However, no other abnormal changes of the thymus were observed in the related test parameters of the histopathological examination, and therefore the changes were deemed not toxicologically significant [40]. In the necropsy findings, changes observed in the main and recovery groups were spontaneous or agonal congestion/hemorrhage due to anesthesia and not related to the administration of PM012.

In the histopathological examination, no noteworthy PM012-related lesions were observed, though some abnormalities were found. The lesions observed in the kidneys, such as glomenulonephropathy, basophilic tubules in the kidneys and hyaline cast, were high in frequency, primarily in males. However, these symptoms are part of chronic progressive nephropathy often observed in rats of approximately 5 months to old age and is particularly frequently observed in males. This nephropathy is accompanied by hyaline cast, which most frequently occurs due to an increase of glomerular penetrability or disorder renal tubular reabsorption. Multifocal alveolar histocytosis was observed in the lungs and is generally characterized by the infiltration of alveolar macrophages with foamy cytoplasm in the pulmonary alveoli near terminal bronchial tubes. This alveolar histocytosis is known to appear when drugs such as aminodarone and iprindole are administered, but it also is known to occur spontaneously in the lungs of rats. All lesions observed in the kidneys and lungs described above were not considered to be changes triggered by the administration of PM012 based on the comparison to the vehicle control group $[38,39,41]$. Furthermore, the diffuse cortical vacuolation observed in the zona fasciculate of the male adrenal gland, the accessory adrenocortical tissue observed in the female adrenal gland, the cyst and pseudocyst observed in the distal pituitary gland, the focal myocarditis observed only in the male heart, the follicular cyst and corpus 
Table 4 Serum biochemical values in rats orally treated with PM012

\begin{tabular}{|c|c|c|c|c|c|c|c|c|c|c|c|c|}
\hline \multirow{3}{*}{ Parameter } & \multirow{3}{*}{ Units } & \multirow{3}{*}{ Sex } & \multicolumn{10}{|c|}{ Dose $(\mathrm{mg} / \mathrm{kg})$} \\
\hline & & & \multicolumn{3}{|c|}{0} & \multicolumn{2}{|c|}{500} & \multicolumn{2}{|c|}{1000} & \multicolumn{3}{|c|}{2000} \\
\hline & & & 4 Weeks & $\begin{array}{c}26 \\
\text { Weeks }\end{array}$ & Recovery & 4 Weeks & $\begin{array}{c}26 \\
\text { Weeks }\end{array}$ & 4 Weeks & $\begin{array}{c}26 \\
\text { Weeks }\end{array}$ & 4 Weeks & $\begin{array}{c}26 \\
\text { Weeks }\end{array}$ & Recovery \\
\hline \multirow[t]{2}{*}{ AST } & $\mathrm{U} / \mathrm{L}$ & Male & $\begin{array}{c}113.90 \pm \\
12.59\end{array}$ & $\begin{array}{c}83.1 \pm \\
11.4\end{array}$ & $\begin{array}{c}90.0 \pm \\
12.8\end{array}$ & $\begin{array}{c}101.98 \pm \\
14.09\end{array}$ & $\begin{array}{c}78.5 \pm \\
9.5\end{array}$ & $\begin{array}{c}94.46 \pm \\
12.02\end{array}$ & $\begin{array}{c}85.9 \pm \\
14.5\end{array}$ & $\begin{array}{c}108.66 \pm \\
24.97\end{array}$ & $\begin{array}{c}84.1 \pm \\
12.7\end{array}$ & $\begin{array}{l}85.1 \pm \\
21.5\end{array}$ \\
\hline & & Female & $\begin{array}{c}97.10 \pm \\
12.99\end{array}$ & $\begin{array}{c}82.0 \pm \\
10.0\end{array}$ & $\begin{array}{c}83.9 \pm \\
17.6\end{array}$ & $\begin{array}{c}102.54 \pm \\
16.78\end{array}$ & $\begin{array}{c}81.9 \pm \\
16.5\end{array}$ & $\begin{array}{c}102.88 \pm \\
7.01\end{array}$ & $\begin{array}{c}81.9 \pm \\
16.6\end{array}$ & $\begin{array}{c}107.64 \pm \\
21.81\end{array}$ & $\begin{array}{c}80.3 \pm \\
9.7\end{array}$ & $\begin{array}{c}81.3 \pm \\
13.2\end{array}$ \\
\hline \multirow[t]{2}{*}{ ALT } & $U / L$ & Male & $\begin{array}{c}35.06 \pm \\
4.56\end{array}$ & $\begin{array}{l}50.3 \pm \\
10.5\end{array}$ & $\begin{array}{l}52.1 \pm \\
10.3\end{array}$ & $\begin{array}{c}34.10 \pm \\
4.28\end{array}$ & $\begin{array}{l}44.3 \pm \\
6.6\end{array}$ & $\begin{array}{c}35.56 \pm \\
4.18\end{array}$ & $\begin{array}{c}48.8 \pm \\
12.9\end{array}$ & $\begin{array}{c}34.68 \pm \\
4.66\end{array}$ & $\begin{array}{c}41.9 \pm \\
6.7\end{array}$ & $\begin{array}{l}52.6 \pm \\
8.4\end{array}$ \\
\hline & & Female & $\begin{array}{c}27.14 \pm \\
3.54\end{array}$ & $\begin{array}{c}37.3 \pm \\
7.8\end{array}$ & $36.4 \pm 3.6$ & $\begin{array}{c}25.96 \pm \\
2.36\end{array}$ & $\begin{array}{c}35.8 \pm \\
3.7\end{array}$ & $\begin{array}{c}27.64 \pm \\
1.90\end{array}$ & $\begin{array}{c}33.4 \pm \\
5.6\end{array}$ & $\begin{array}{c}27.06 \pm \\
1.64\end{array}$ & $\begin{array}{l}36.1 \pm \\
6.5\end{array}$ & $\begin{array}{c}35.2 \pm \\
3.9\end{array}$ \\
\hline \multirow[t]{2}{*}{ ALP } & $\mathrm{U} / \mathrm{L}$ & Male & $\begin{array}{c}133.96 \pm \\
13.75\end{array}$ & $\begin{array}{c}76.7 \pm \\
11.9\end{array}$ & $\begin{array}{c}84.6 \pm \\
11.9\end{array}$ & $\begin{array}{c}124.38 \pm \\
9.96\end{array}$ & $\begin{array}{c}77.0 \pm \\
11.0\end{array}$ & $\begin{array}{c}126.12 \pm \\
9.52\end{array}$ & $\begin{array}{c}79.5 \pm \\
14.9\end{array}$ & $\begin{array}{c}147.08 \pm \\
19.36\end{array}$ & $\begin{array}{c}73.1 \pm \\
12.2\end{array}$ & $\begin{array}{c}91.1 \pm \\
9.1\end{array}$ \\
\hline & & Female & $\begin{array}{c}87.20 \pm \\
10.59\end{array}$ & $\begin{array}{c}57.9 \pm \\
12.2\end{array}$ & $54.1 \pm 8.7$ & $\begin{array}{c}92.66 \pm \\
15.55\end{array}$ & $\begin{array}{c}62.3 \pm \\
28.8\end{array}$ & $\begin{array}{c}99.04 \pm \\
18.32\end{array}$ & $\begin{array}{c}50.6 \pm \\
16.5\end{array}$ & $\begin{array}{c}88.48 \pm \\
3.48\end{array}$ & $\begin{array}{l}54.7 \pm \\
11.5\end{array}$ & $\begin{array}{c}58.4 \pm \\
13.4\end{array}$ \\
\hline \multirow[t]{2}{*}{ CPK } & $\mathrm{U} / \mathrm{L}$ & Male & $\begin{array}{c}408.4 \pm \\
68.2\end{array}$ & $\begin{array}{l}101.6 \pm \\
25.6\end{array}$ & $\begin{array}{c}199.8 \pm \\
118.8\end{array}$ & $\begin{array}{c}291.6 \pm \\
96.3\end{array}$ & $\begin{array}{c}98.9 \pm \\
20.5\end{array}$ & $\begin{array}{c}212.4 \pm \\
92.1\end{array}$ & $\begin{array}{c}114.7 \pm \\
49.5\end{array}$ & $\begin{array}{c}261.0 \pm \\
152.6\end{array}$ & $\begin{array}{c}122.8 \pm \\
65.9\end{array}$ & $\begin{array}{c}135.2 \pm \\
64.9\end{array}$ \\
\hline & & Female & $\begin{array}{c}265.8 \pm \\
110.2\end{array}$ & $\begin{array}{c}104.1 \pm \\
31.7\end{array}$ & $\begin{array}{c}143.8 \pm \\
70.5\end{array}$ & $\begin{array}{c}266.6 \pm \\
142.2\end{array}$ & $\begin{array}{c}87.2 \pm \\
45.2\end{array}$ & $\begin{array}{c}227.8 \pm \\
78.6\end{array}$ & $\begin{array}{c}81.9 \pm \\
28.9\end{array}$ & $\begin{array}{c}282.0 \pm \\
148.6\end{array}$ & $\begin{array}{c}85.0 \pm \\
33.1\end{array}$ & $\begin{array}{c}161.2 \pm \\
68.4\end{array}$ \\
\hline \multirow[t]{2}{*}{ BIL } & $\mathrm{mg} / \mathrm{dL}$ & Male & $0.21 \pm 0.00$ & $\begin{array}{l}0.19 \pm \\
0.02\end{array}$ & $\begin{array}{l}0.19 \pm \\
0.02\end{array}$ & $0.21 \pm 0.00$ & $\begin{array}{l}0.21 \pm \\
0.02\end{array}$ & $\begin{array}{c}0.20 \pm \\
0.01\end{array}$ & $\begin{array}{c}0.19 \pm \\
0.01\end{array}$ & $0.21 \pm 0.01$ & $\begin{array}{l}0.20 \pm \\
0.02\end{array}$ & $\begin{array}{c}0.20 \pm \\
0.01\end{array}$ \\
\hline & & Female & $0.21 \pm 0.02$ & $\begin{array}{l}0.23 \pm \\
0.03\end{array}$ & $\begin{array}{l}0.26 \pm \\
0.04\end{array}$ & $0.23 \pm 0.02$ & $\begin{array}{l}0.23 \pm \\
0.03\end{array}$ & $\begin{array}{l}0.22 \pm \\
0.02\end{array}$ & $\begin{array}{l}0.23 \pm \\
0.03\end{array}$ & $0.23 \pm 0.02$ & $\begin{array}{l}0.24 \pm \\
0.02\end{array}$ & $\begin{array}{l}0.26 \pm \\
0.05\end{array}$ \\
\hline \multirow[t]{2}{*}{ GLU } & $\mathrm{mg} / \mathrm{dL}$ & Male & $\begin{array}{c}102.18 \pm \\
9.12\end{array}$ & $\begin{array}{c}116.8 \pm \\
9.1\end{array}$ & $\begin{array}{c}120.5 \pm \\
9.5\end{array}$ & $\begin{array}{l}99.94 \pm \\
5.77\end{array}$ & $\begin{array}{c}121.3 \pm \\
12.3\end{array}$ & $\begin{array}{c}108.70 \pm \\
9.87\end{array}$ & $\begin{array}{c}113.7 \pm \\
11.4\end{array}$ & $\begin{array}{c}109.38 \pm \\
8.60\end{array}$ & $\begin{array}{c}113.3 \pm \\
9.8\end{array}$ & $\begin{array}{c}121.0 \pm \\
8.4\end{array}$ \\
\hline & & Female & $\begin{array}{c}106.66 \pm \\
7.29\end{array}$ & $\begin{array}{c}107.6 \pm \\
10.7\end{array}$ & $\begin{array}{c}130.5 \pm \\
14.1\end{array}$ & $\begin{array}{c}99.86 \pm \\
3.54\end{array}$ & $\begin{array}{l}111.6 \pm \\
15.7\end{array}$ & $\begin{array}{c}100.10 \pm \\
5.58\end{array}$ & $\begin{array}{c}110.0 \pm \\
11.2\end{array}$ & $\begin{array}{c}99.30 \pm \\
9.04\end{array}$ & $\begin{array}{c}106.2 \pm \\
12.2\end{array}$ & $\begin{array}{c}132.0 \pm \\
7.4\end{array}$ \\
\hline \multirow[t]{2}{*}{$\mathrm{CHO}$} & $\mathrm{mg} / \mathrm{dL}$ & Male & $90.4 \pm 6.6$ & $\begin{array}{c}139.5 \pm \\
27.3\end{array}$ & $\begin{array}{c}165.0 \pm \\
46.6\end{array}$ & $93.2 \pm 12.8$ & $\begin{array}{c}152.9 \pm \\
46.8\end{array}$ & $95.6 \pm 9.4$ & $\begin{array}{c}123.2 \pm \\
26.6\end{array}$ & $84.6 \pm 9.9$ & $\begin{array}{c}116.0 \pm \\
25.2\end{array}$ & $\begin{array}{c}180.2 \pm \\
73.0\end{array}$ \\
\hline & & Female & $96.8 \pm 13.2$ & $\begin{array}{c}118.9 \pm \\
13.0\end{array}$ & $\begin{array}{c}119.0 \pm \\
20.9\end{array}$ & $96.4 \pm 20.6$ & $\begin{array}{c}119.1 \pm \\
33.0\end{array}$ & $\begin{array}{c}98.0 \pm \\
11.6\end{array}$ & $\begin{array}{c}138.5 \pm \\
34.5\end{array}$ & $98.2 \pm 17.2$ & $\begin{array}{c}126.4 \pm \\
28.2\end{array}$ & $\begin{array}{c}131.4 \pm \\
24.5\end{array}$ \\
\hline \multirow[t]{2}{*}{ TG } & $\mathrm{mg} / \mathrm{dL}$ & Male & $45.2 \pm 8.2$ & $\begin{array}{l}49.6 \pm \\
8.3\end{array}$ & $\begin{array}{c}54.8 \pm \\
18.9\end{array}$ & $46.8 \pm 11.1$ & $\begin{array}{c}61.1 \pm \\
20.2\end{array}$ & $44.4 \pm 7.1$ & $\begin{array}{c}46.0 \pm \\
10.4\end{array}$ & $46.4 \pm 7.4$ & $\begin{array}{l}47.7 \pm \\
7.3\end{array}$ & $\begin{array}{c}63.4 \pm \\
34.0\end{array}$ \\
\hline & & Female & $36.0 \pm 8.1$ & $\begin{array}{l}43.5 \pm \\
5.5\end{array}$ & $39.6 \pm 5.3$ & $36.4 \pm 7.7$ & $\begin{array}{l}43.2 \pm \\
6.6\end{array}$ & $36.2 \pm 4.1$ & $\begin{array}{l}48.1 \pm \\
6.5\end{array}$ & $39.4 \pm 6.5$ & $\begin{array}{c}47.6 \pm \\
9.0\end{array}$ & $\begin{array}{c}44.0 \pm \\
13.1\end{array}$ \\
\hline \multirow[t]{2}{*}{ PRO } & $\mathrm{g} / \mathrm{dL}$ & Male & $6.04 \pm 0.10$ & $\begin{array}{l}6.54 \pm \\
0.14\end{array}$ & $\begin{array}{c}6.38 \pm \\
0.17\end{array}$ & $5.99 \pm 0.23$ & $\begin{array}{c}6.48 \pm \\
0.19\end{array}$ & $\begin{array}{l}5.97 \pm \\
0.10\end{array}$ & $\begin{array}{l}6.42 \pm \\
0.13\end{array}$ & $5.99 \pm 0.24$ & $\begin{array}{c}6.50 \pm \\
0.17\end{array}$ & $\begin{array}{c}6.60 \pm \\
0.21\end{array}$ \\
\hline & & Female & $5.63 \pm 0.23$ & $\begin{array}{l}6.37 \pm \\
0.16\end{array}$ & $\begin{array}{l}6.84 \pm \\
0.33\end{array}$ & $5.81 \pm 0.38$ & $\begin{array}{l}6.65 \pm \\
0.35\end{array}$ & $\begin{array}{l}5.71 \pm \\
0.23\end{array}$ & $\begin{array}{l}6.60 \pm \\
0.30\end{array}$ & $5.79 \pm 0.13$ & $\begin{array}{l}6.76 \pm \\
0.32\end{array}$ & $\begin{array}{l}6.53 \pm \\
0.20\end{array}$ \\
\hline \multirow[t]{2}{*}{ ALB } & $\mathrm{g} / \mathrm{dL}$ & Male & $3.17 \pm 0.05$ & $\begin{array}{c}2.99 \pm \\
0.10\end{array}$ & $\begin{array}{l}2.85 \pm \\
0.14\end{array}$ & $3.14 \pm 0.08$ & $\begin{array}{c}2.95 \pm \\
0.11\end{array}$ & $\begin{array}{l}3.15 \pm \\
0.04\end{array}$ & $\begin{array}{l}2.97 \pm \\
0.07\end{array}$ & $3.18 \pm 0.11$ & $\begin{array}{l}3.07 \pm \\
0.12\end{array}$ & $\begin{array}{c}2.83 \pm \\
0.21\end{array}$ \\
\hline & & Female & $3.05 \pm 0.11$ & $\begin{array}{c}3.16 \pm \\
0.10\end{array}$ & $\begin{array}{c}3.44 \pm \\
0.26\end{array}$ & $3.16 \pm 0.12$ & $\begin{array}{c}3.34 \pm \\
0.12\end{array}$ & $\begin{array}{c}3.08 \pm \\
0.09\end{array}$ & $\begin{array}{c}3.27 \pm \\
0.19\end{array}$ & $3.14 \pm 0.04$ & $\begin{array}{c}3.38 \pm \\
0.20\end{array}$ & $\begin{array}{c}3.25 \pm \\
0.16\end{array}$ \\
\hline \multirow[t]{2}{*}{$A / G$} & ratio & Male & $1.10 \pm 0.00$ & $\begin{array}{l}0.84 \pm \\
0.03\end{array}$ & $\begin{array}{l}0.81 \pm \\
0.09\end{array}$ & $1.10 \pm 0.04$ & $\begin{array}{l}0.84 \pm \\
0.08\end{array}$ & $\begin{array}{l}1.12 \pm \\
0.02\end{array}$ & $\begin{array}{l}0.86 \pm \\
0.05\end{array}$ & $1.14 \pm 0.03$ & $\begin{array}{l}0.90 \pm \\
0.06\end{array}$ & $\begin{array}{c}0.76 \pm \\
0.11\end{array}$ \\
\hline & & Female & $1.19 \pm 0.05$ & $\begin{array}{l}0.98 \pm \\
0.06\end{array}$ & $\begin{array}{l}1.01 \pm \\
0.10\end{array}$ & $1.20 \pm 0.10$ & $\begin{array}{l}1.01 \pm \\
0.05\end{array}$ & $\begin{array}{l}1.17 \pm \\
0.05\end{array}$ & $\begin{array}{l}0.98 \pm \\
0.05\end{array}$ & $1.18 \pm 0.05$ & $\begin{array}{l}1.00 \pm \\
0.05\end{array}$ & $\begin{array}{l}0.99 \pm \\
0.05\end{array}$ \\
\hline \multirow[t]{2}{*}{ BUN } & $\mathrm{mg} / \mathrm{dL}$ & Male & $\begin{array}{c}16.94 \pm \\
1.66\end{array}$ & $\begin{array}{l}16.0 \pm \\
2.7\end{array}$ & $17.1 \pm 3.5$ & $\begin{array}{c}15.26 \pm \\
1.69\end{array}$ & $\begin{array}{c}16.4 \pm \\
2.1\end{array}$ & $\begin{array}{c}14.52 \pm \\
1.38\end{array}$ & $\begin{array}{l}15.8 \pm \\
2.3\end{array}$ & $\begin{array}{l}15.86 \pm \\
1.88\end{array}$ & $\begin{array}{l}14.7 \pm \\
2.4\end{array}$ & $\begin{array}{c}16.9 \pm \\
2.9\end{array}$ \\
\hline & & Female & $\begin{array}{l}16.48 \pm \\
1.47\end{array}$ & $\begin{array}{c}17.5 \pm \\
1.2\end{array}$ & $15.2 \pm 2.0$ & $\begin{array}{c}16.60 \pm \\
1.02\end{array}$ & $\begin{array}{c}17.3 \pm \\
1.1\end{array}$ & $\begin{array}{c}16.24 \pm \\
1.39\end{array}$ & $\begin{array}{c}17.7 \pm \\
1.9\end{array}$ & $\begin{array}{c}17.14 \pm \\
0.66\end{array}$ & $\begin{array}{c}16.9 \pm \\
1.9\end{array}$ & $\begin{array}{c}14.6 \pm \\
1.5\end{array}$ \\
\hline \multirow[t]{2}{*}{ CRE } & $\mathrm{mg} / \mathrm{dL}$ & Male & $0.48 \pm 0.07$ & $\begin{array}{l}0.57 \pm \\
0.08\end{array}$ & $\begin{array}{c}0.59 \pm \\
0.07\end{array}$ & $0.49 \pm 0.03$ & $\begin{array}{l}0.60 \pm \\
0.04\end{array}$ & $\begin{array}{l}0.48 \pm \\
0.02\end{array}$ & $\begin{array}{l}0.56 \pm \\
0.03\end{array}$ & $0.50 \pm 0.02$ & $\begin{array}{l}0.56 \pm \\
0.02\end{array}$ & $\begin{array}{l}0.62 \pm \\
0.07\end{array}$ \\
\hline & & Female & $0.50 \pm 0.03$ & $\begin{array}{l}0.63 \pm \\
0.03\end{array}$ & $\begin{array}{c}0.62 \pm \\
0.04\end{array}$ & $0.52 \pm 0.04$ & $\begin{array}{l}0.64 \pm \\
0.05\end{array}$ & $\begin{array}{l}0.53 \pm \\
0.05\end{array}$ & $\begin{array}{c}0.68 \pm \\
0.07\end{array}$ & $0.53 \pm 0.03$ & $\begin{array}{l}0.65 \pm \\
0.05\end{array}$ & $\begin{array}{c}0.61 \pm \\
0.02\end{array}$ \\
\hline $\mathbb{I P}$ & $\mathrm{mg} / \mathrm{dL}$ & Male & $8.57 \pm 0.35$ & $\begin{array}{c}5.96 \pm \\
0.38\end{array}$ & $\begin{array}{c}5.92 \pm \\
0.53\end{array}$ & $8.59 \pm 0.14$ & $\begin{array}{c}6.16 \pm \\
0.36\end{array}$ & $\begin{array}{c}8.43 \pm \\
0.42\end{array}$ & $\begin{array}{c}6.08 \pm \\
0.44\end{array}$ & $8.76 \pm 0.39$ & $\begin{array}{c}6.37 \pm \\
0.59\end{array}$ & $\begin{array}{c}6.13 \pm \\
0.14\end{array}$ \\
\hline
\end{tabular}


Table 4 Serum biochemical values in rats orally treated with PM012 (Continued)

\begin{tabular}{|c|c|c|c|c|c|c|c|c|c|c|c|c|}
\hline & & Female & $8.08 \pm 0.62$ & $\begin{array}{c}5.69 \pm \\
0.86\end{array}$ & $\begin{array}{c}4.43 \pm \\
0.28\end{array}$ & $7.96 \pm 0.58$ & $\begin{array}{c}5.17 \pm \\
1.28\end{array}$ & $\begin{array}{c}8.08 \pm \\
0.50\end{array}$ & $\begin{array}{c}5.53 \pm \\
0.71\end{array}$ & $7.95 \pm 0.38$ & $\begin{array}{c}5.76 \pm \\
0.79\end{array}$ & $\begin{array}{c}4.68 \pm \\
0.24\end{array}$ \\
\hline \multirow[t]{2}{*}{$\mathrm{Ca}^{2+}$} & $\mathrm{mg} / \mathrm{dL}$ & Male & $\begin{array}{c}10.53 \pm \\
0.14\end{array}$ & $\begin{array}{c}10.48 \pm \\
0.15\end{array}$ & $\begin{array}{c}10.30 \pm \\
0.28\end{array}$ & $\begin{array}{c}10.47 \pm \\
0.21\end{array}$ & $\begin{array}{c}10.41 \pm \\
0.20\end{array}$ & $\begin{array}{c}10.40 \pm \\
0.18\end{array}$ & $\begin{array}{c}10.26 \pm \\
0.09\end{array}$ & $\begin{array}{c}10.34 \pm \\
0.25\end{array}$ & $\begin{array}{c}10.32 \pm \\
0.13\end{array}$ & $\begin{array}{c}10.39 \pm \\
0.05\end{array}$ \\
\hline & & Female & $\begin{array}{c}10.08 \pm \\
0.25\end{array}$ & $\begin{array}{c}10.08 \pm \\
0.21\end{array}$ & $\begin{array}{c}10.48 \pm \\
0.34\end{array}$ & $\begin{array}{c}10.05 \pm \\
0.22\end{array}$ & $\begin{array}{c}10.19 \pm \\
0.31\end{array}$ & $\begin{array}{c}10.03 \pm \\
0.32\end{array}$ & $\begin{array}{c}10.13 \pm \\
0.22\end{array}$ & $9.81 \pm 0.18$ & $\begin{array}{c}10.20 \pm \\
0.22\end{array}$ & $\begin{array}{c}10.21 \pm \\
0.28\end{array}$ \\
\hline \multirow[t]{2}{*}{$\mathrm{Na}^{+}$} & $\underset{\mathrm{L}}{\mathrm{mmol} /}$ & Male & $148.2 \pm 0.8$ & $\begin{array}{c}145.3 \pm \\
0.9\end{array}$ & $\begin{array}{c}143.9 \pm \\
1.2\end{array}$ & $148.2 \pm 0.8$ & $\begin{array}{c}144.7 \pm \\
1.0\end{array}$ & $\begin{array}{c}148.2 \pm \\
1.3\end{array}$ & $\begin{array}{c}144.5 \pm \\
0.8\end{array}$ & $148.6 \pm 0.9$ & $\begin{array}{c}145.3 \pm \\
1.3\end{array}$ & $\begin{array}{c}143.2 \pm \\
0.7\end{array}$ \\
\hline & & Female & $146.2 \pm 1.3$ & $\begin{array}{c}145.0 \pm \\
0.9\end{array}$ & $\begin{array}{c}141.9 \pm \\
1.1\end{array}$ & $145.2 \pm 2.4$ & $\begin{array}{c}144.1 \pm \\
1.2\end{array}$ & $\begin{array}{c}143.8 \pm \\
0.8\end{array}$ & $\begin{array}{c}143.5 \pm \\
1.3\end{array}$ & $144.0 \pm 1.0$ & $\begin{array}{c}143.5 \pm \\
0.9\end{array}$ & $\begin{array}{c}142.0 \pm \\
1.1\end{array}$ \\
\hline \multirow[t]{2}{*}{$\mathrm{K}^{+}$} & $\underset{\mathrm{L}}{\mathrm{mmol} /}$ & Male & $4.82 \pm 0.13$ & $\begin{array}{c}4.32 \pm \\
0.18\end{array}$ & $\begin{array}{c}4.57 \pm \\
0.23\end{array}$ & $4.71 \pm 0.22$ & $\begin{array}{c}4.19 \pm \\
0.17\end{array}$ & $\begin{array}{c}4.75 \pm \\
0.12\end{array}$ & $\begin{array}{c}4.36 \pm \\
0.20\end{array}$ & $4.72 \pm 0.14$ & $\begin{array}{c}4.31 \pm \\
0.21\end{array}$ & $\begin{array}{c}4.37 \pm \\
0.25\end{array}$ \\
\hline & & Female & $4.71 \pm 0.16$ & $\begin{array}{c}3.99 \pm \\
0.15\end{array}$ & $\begin{array}{c}3.99 \pm \\
0.24\end{array}$ & $4.52 \pm 0.16$ & $\begin{array}{c}4.36 \pm \\
1.08\end{array}$ & $\begin{array}{c}4.53 \pm \\
0.11\end{array}$ & $\begin{array}{c}4.20 \pm \\
1.08\end{array}$ & $4.53 \pm 0.43$ & $\begin{array}{c}4.04 \pm \\
0.29\end{array}$ & $\begin{array}{c}3.96 \pm \\
0.32\end{array}$ \\
\hline \multirow[t]{2}{*}{$\mathrm{Cl}^{-}$} & $\underset{\mathrm{L}}{\mathrm{mmol} /}$ & Male & $108.8 \pm 0.4$ & $\begin{array}{c}105.7 \pm \\
0.7\end{array}$ & $\begin{array}{c}104.5 \pm \\
1.2\end{array}$ & $108.4 \pm 1.1$ & $\begin{array}{c}105.0 \pm \\
1.8\end{array}$ & $\begin{array}{c}108.2 \pm \\
0.8\end{array}$ & $\begin{array}{c}106.1 \pm \\
0.9\end{array}$ & $108.6 \pm 0.5$ & $\begin{array}{c}105.2 \pm \\
1.1\end{array}$ & $\begin{array}{c}103.5 \pm \\
1.0\end{array}$ \\
\hline & & Female & $109.2 \pm 0.8$ & $\begin{array}{c}106.5 \pm \\
1.4\end{array}$ & $\begin{array}{c}104.6 \pm \\
0.9\end{array}$ & $109.2 \pm 0.8$ & $\begin{array}{c}107.1 \pm \\
0.7\end{array}$ & $\begin{array}{c}108.0 \pm \\
1.2\end{array}$ & $\begin{array}{c}106.4 \pm \\
0.9\end{array}$ & $108.2 \pm 0.8$ & $\begin{array}{c}105.9 \pm \\
1.1\end{array}$ & $\begin{array}{c}104.7 \pm \\
1.5\end{array}$ \\
\hline
\end{tabular}

*AST (Aspartate aminotransferase), ALT (Alanine aminotransferase), ALP (Alkaline phosphatase), CPK (Creatine phosphokinase), BIL (Total bilirubin), GLU (Glucose), CHO (Total cholesterol), TG (Triglyceride), PRO (Total protein), ALB (Albumin), A/G ratio (Albumin/Globulin ratio), BUN (Blood urea nitrogen), CRE (Creatinine), IP (Inorganic phosphorus), $\mathrm{Ca}^{2+}$ (Calcium ion), $\mathrm{Na}^{+}$(Sodium ion), $\mathrm{K}^{+}$(Potassium ion), $\mathrm{Cl}^{-}$(Chloride ion).

Values are mean \pm SD ( $n=5$ ( 4 weeks) or 10 (26 weks)/sex/dose). $\mathrm{P}<0.05$ compare with normal group.

Table 5 Absolute \& relative organ weights in rats orally treated with PM012

\begin{tabular}{|c|c|c|c|c|c|c|c|c|c|c|c|}
\hline \multirow{3}{*}{ Parameter } & \multirow{3}{*}{ Sex } & \multicolumn{10}{|c|}{ Dose $(\mathrm{mg} / \mathrm{kg})$} \\
\hline & & \multicolumn{3}{|c|}{0} & \multicolumn{2}{|c|}{500} & \multicolumn{2}{|c|}{1000} & \multicolumn{3}{|c|}{2000} \\
\hline & & 4 Weeks & 26 Weeks & Recovery & 4 Weeks & 26 Weeks & 4 Weeks & 26 Weeks & 4 Weeks & 26 Weeks & Recovery \\
\hline \multirow[t]{2}{*}{$\begin{array}{c}\text { Body } \\
\text { weight }\end{array}$} & Male & $\begin{array}{c}326.79 \pm \\
18.46\end{array}$ & $\begin{array}{c}484.71 \pm \\
33.01\end{array}$ & $\begin{array}{c}502.94 \pm \\
17.59\end{array}$ & $\begin{array}{c}321.28 \pm \\
20.83\end{array}$ & $\begin{array}{c}504.38 \pm \\
45.11\end{array}$ & $\begin{array}{c}330.67 \pm \\
23.75\end{array}$ & $\begin{array}{c}474.08 \pm \\
46.03\end{array}$ & $\begin{array}{c}324.80 \pm \\
15.32\end{array}$ & $\begin{array}{c}468.68 \pm \\
35.08\end{array}$ & $\begin{array}{c}507.84 \pm \\
32.08\end{array}$ \\
\hline & Female & $\begin{array}{c}194.35 \pm \\
7.86\end{array}$ & $\begin{array}{c}268.94 \pm \\
12.88\end{array}$ & $\begin{array}{c}277.90 \pm \\
26.72\end{array}$ & $\begin{array}{c}195.07 \pm \\
9.64\end{array}$ & $\begin{array}{c}270.36 \pm \\
13.17\end{array}$ & $\begin{array}{c}196.26 \pm \\
12.33\end{array}$ & $\begin{array}{c}272.81 \pm \\
19.48\end{array}$ & $\begin{array}{c}195.04 \pm \\
14.05\end{array}$ & $\begin{array}{c}264.92 \pm \\
17.98\end{array}$ & $\begin{array}{c}279.89 \pm \\
6.03\end{array}$ \\
\hline \multirow[t]{2}{*}{$\begin{array}{l}\text { Adrenal } \\
\text { grand (Lt.) }\end{array}$} & Male & $\begin{array}{c}0.0266 \pm \\
0.0032\end{array}$ & $\begin{array}{c}0.0258 \pm \\
0.0025\end{array}$ & $\begin{array}{c}0.0276 \pm \\
0.0037\end{array}$ & $\begin{array}{c}0.0260 \pm \\
0.0033\end{array}$ & $\begin{array}{c}0.0254 \pm \\
0.0031\end{array}$ & $\begin{array}{c}0.0265 \pm \\
0.0025\end{array}$ & $\begin{array}{c}0.0245 \pm \\
0.0022\end{array}$ & $\begin{array}{c}0.0290 \pm \\
0.0011\end{array}$ & $\begin{array}{c}0.0243 \pm \\
0.0031\end{array}$ & $\begin{array}{c}0.0271 \pm \\
0.0037\end{array}$ \\
\hline & Female & $\begin{array}{c}0.0312 \pm \\
0.0025\end{array}$ & $\begin{array}{c}0.0311 \pm \\
0.0038\end{array}$ & $\begin{array}{c}0.0309 \pm \\
0.0054\end{array}$ & $\begin{array}{c}0.0309 \pm \\
0.0023\end{array}$ & $\begin{array}{c}0.0325 \pm \\
0.0039\end{array}$ & $\begin{array}{c}0.0333 \pm \\
0.0025\end{array}$ & $\begin{array}{c}0.0313 \pm \\
0.0056\end{array}$ & $\begin{array}{c}0.0314 \pm \\
0.0038\end{array}$ & $\begin{array}{c}0.0310 \pm \\
0.0050\end{array}$ & $\begin{array}{c}0.0326 \pm \\
0.0053\end{array}$ \\
\hline \multirow[t]{2}{*}{$\begin{array}{c}\% \text { to body } \\
\text { weight }\end{array}$} & Male & $\begin{array}{c}0.0082 \pm \\
0.0014\end{array}$ & $\begin{array}{c}0.0054 \pm \\
0.0007\end{array}$ & $\begin{array}{c}0.0055 \pm \\
0.0007\end{array}$ & $\begin{array}{c}0.0081 \pm \\
0.0009\end{array}$ & $\begin{array}{c}0.0050 \pm \\
0.0005\end{array}$ & $\begin{array}{c}0.0080 \pm \\
0.0005\end{array}$ & $\begin{array}{c}0.0052 \pm \\
0.0006\end{array}$ & $\begin{array}{c}0.0089 \pm \\
0.0007\end{array}$ & $\begin{array}{c}0.0052 \pm \\
0.0006\end{array}$ & $\begin{array}{c}0.0053 \pm \\
0.0005\end{array}$ \\
\hline & Female & $\begin{array}{c}0.0161 \pm \\
0.0016\end{array}$ & $\begin{array}{l}0.0115 \pm \\
0.0013\end{array}$ & $\begin{array}{c}0.0112 \pm \\
0.0022\end{array}$ & $\begin{array}{c}0.0158 \pm \\
0.0008\end{array}$ & $\begin{array}{l}0.0120 \pm \\
0.0013\end{array}$ & $\begin{array}{c}0.0170 \pm \\
0.0010\end{array}$ & $\begin{array}{c}0.0115 \pm \\
0.0019\end{array}$ & $\begin{array}{c}0.0162 \pm \\
0.0023\end{array}$ & $\begin{array}{c}0.0117 \pm \\
0.0020\end{array}$ & $\begin{array}{c}0.0117 \pm \\
0.0019\end{array}$ \\
\hline \multirow[t]{2}{*}{$\begin{array}{l}\text { Adrenal } \\
\text { grand (Rt.) }\end{array}$} & Male & $\begin{array}{c}0.0274 \pm \\
0.0015\end{array}$ & $\begin{array}{c}0.0247 \pm \\
0.0027\end{array}$ & $\begin{array}{c}0.0289 \pm \\
0.0025\end{array}$ & $\begin{array}{c}0.0255 \pm \\
0.0015\end{array}$ & $\begin{array}{c}0.0252 \pm \\
0.0030\end{array}$ & $\begin{array}{c}0.0246 \pm \\
0.0046\end{array}$ & $\begin{array}{c}0.0224 \pm \\
0.0034\end{array}$ & $\begin{array}{c}0.0264 \pm \\
0.0026\end{array}$ & $\begin{array}{c}0.0246 \pm \\
0.0026\end{array}$ & $\begin{array}{c}0.0278 \pm \\
0.0054\end{array}$ \\
\hline & Female & $\begin{array}{c}0.0305 \pm \\
0.0023\end{array}$ & $\begin{array}{c}0.0295 \pm \\
0.0030\end{array}$ & $\begin{array}{c}0.0296 \pm \\
0.0059\end{array}$ & $\begin{array}{c}0.0308 \pm \\
0.0045\end{array}$ & $\begin{array}{c}0.0306 \pm \\
0.0033\end{array}$ & $\begin{array}{c}0.0305 \pm \\
0.0019\end{array}$ & $\begin{array}{c}0.0301 \pm \\
0.0052\end{array}$ & $\begin{array}{c}0.0313 \pm \\
0.0041\end{array}$ & $\begin{array}{c}00287 \pm \\
0.0042\end{array}$ & $\begin{array}{c}0.0314 \pm \\
0.0048\end{array}$ \\
\hline \multirow[t]{2}{*}{$\begin{array}{c}\% \text { to body } \\
\text { weight }\end{array}$} & Male & $\begin{array}{c}0.0084 \pm \\
0.0008\end{array}$ & $\begin{array}{c}0.0051 \pm \\
0.0006\end{array}$ & $\begin{array}{c}0.0057 \pm \\
0.0005\end{array}$ & $\begin{array}{c}0.0080 \pm \\
0.0003\end{array}$ & $\begin{array}{c}0.0050 \pm \\
0.0003\end{array}$ & $\begin{array}{c}0.0074 \pm \\
0.0012\end{array}$ & $\begin{array}{c}0.0048 \pm \\
0.0009\end{array}$ & $\begin{array}{c}0.0081 \pm \\
0.0009\end{array}$ & $\begin{array}{c}0.0053 \pm \\
0.0006\end{array}$ & $\begin{array}{c}0.0055 \pm \\
0.0009\end{array}$ \\
\hline & Female & $\begin{array}{c}0.0157 \pm \\
0.0013\end{array}$ & $\begin{array}{l}0.0110 \pm \\
0.0013\end{array}$ & $\begin{array}{c}0.0108 \pm \\
0.0026\end{array}$ & $\begin{array}{c}0.0158 \pm \\
0.0020\end{array}$ & $\begin{array}{c}0.0113 \pm \\
0.0010\end{array}$ & $\begin{array}{c}0.0156 \pm \\
0.0017\end{array}$ & $\begin{array}{c}0.0110 \pm \\
0.0019\end{array}$ & $\begin{array}{c}0.0160 \pm \\
0.0019\end{array}$ & $\begin{array}{c}0.0109 \pm \\
0.0018\end{array}$ & $\begin{array}{c}0.0112 \pm \\
0.0018\end{array}$ \\
\hline \multirow[t]{2}{*}{$\begin{array}{l}\text { Pituitary } \\
\text { grand }\end{array}$} & Male & $N D^{b)}$ & $\begin{array}{c}0.0128 \pm \\
0.0010\end{array}$ & $\begin{array}{c}0.0135 \pm \\
0.0017\end{array}$ & $N D^{b)}$ & $\begin{array}{c}0.0126 \pm \\
0.0011\end{array}$ & $N D^{b)}$ & $\begin{array}{c}0.0126 \pm \\
0.0013\end{array}$ & $N D^{b)}$ & $\begin{array}{c}0.0124 \pm \\
0.0009\end{array}$ & $\begin{array}{c}0.0135 \pm \\
0.0014\end{array}$ \\
\hline & Female & $N D^{b)}$ & $\begin{array}{c}0.0151 \pm \\
0.0017\end{array}$ & $\begin{array}{c}0.0153 \pm \\
0.0011\end{array}$ & $N D^{b)}$ & $\begin{array}{c}0.0150 \pm \\
0.0022\end{array}$ & $N D^{b)}$ & $\begin{array}{c}0.0170 \pm \\
0.0042\end{array}$ & $N D^{b)}$ & $\begin{array}{c}0.0143 \pm \\
0.0021\end{array}$ & $\begin{array}{c}0.0160 \pm \\
0.0017\end{array}$ \\
\hline \multirow[t]{2}{*}{$\begin{array}{c}\% \text { to body } \\
\text { weight }\end{array}$} & Male & $N D^{b)}$ & $\begin{array}{c}0.0026 \pm \\
0.0002\end{array}$ & $\begin{array}{c}0.0027 \pm \\
0.0004\end{array}$ & $N D^{b)}$ & $\begin{array}{c}0.0025 \pm \\
0.0002\end{array}$ & $N D^{b)}$ & $\begin{array}{c}0.0027 \pm \\
0.0002\end{array}$ & $N D^{b)}$ & $\begin{array}{c}0.0027 \pm \\
0.0001\end{array}$ & $\begin{array}{c}0.0027 \pm \\
0.0002\end{array}$ \\
\hline & Female & $N D^{b)}$ & $\begin{array}{c}0.0056 \pm \\
0.0005\end{array}$ & $\begin{array}{c}0.0056 \pm \\
0.0007\end{array}$ & $N D^{b)}$ & $\begin{array}{c}0.0055 \pm \\
0.0009\end{array}$ & $N D^{b)}$ & $\begin{array}{c}0.0062 \pm \\
0.0015\end{array}$ & $N D^{b)}$ & $\begin{array}{c}0.0054 \pm \\
0.0009\end{array}$ & $\begin{array}{l}0.0057 \pm \\
0.0005\end{array}$ \\
\hline Thymus & Male & $\begin{array}{c}0.4132 \pm \\
0.0579\end{array}$ & $\begin{array}{c}0.1887 \pm \\
0.0403\end{array}$ & $\begin{array}{c}0.1668 \pm \\
0.0116\end{array}$ & $\begin{array}{c}0.5040 \pm \\
0.0841\end{array}$ & $\begin{array}{c}0.2201 \pm \\
0.0349\end{array}$ & $\begin{array}{c}0.4522 \pm \\
0.0657\end{array}$ & $\begin{array}{c}0.2055 \pm \\
0.0585\end{array}$ & $\begin{array}{c}0.4942 \pm \\
0.0904\end{array}$ & $\begin{array}{c}0.1981 \pm \\
0.0361\end{array}$ & $\begin{array}{c}0.1520 \pm \\
0.0308\end{array}$ \\
\hline
\end{tabular}


Table 5 Absolute \& relative organ weights in rats orally treated with PM012 (Continued)

\begin{tabular}{|c|c|c|c|c|c|c|c|c|c|c|c|}
\hline & Female & $\begin{array}{c}0.2837 \pm \\
0.0195\end{array}$ & $\begin{array}{c}0.1380 \pm \\
0.0191\end{array}$ & $\begin{array}{c}0.1320 \pm \\
0.0144\end{array}$ & $\begin{array}{c}0.3389 \pm \\
0.0336\end{array}$ & $\begin{array}{c}0.1418 \pm \\
0.0126\end{array}$ & $\begin{array}{c}0.3124 \pm \\
0.0420\end{array}$ & $\begin{array}{c}0.1535 \pm \\
0.0347\end{array}$ & $\begin{array}{c}0.3372 \pm \\
0.0316\end{array}$ & $\begin{array}{c}0.1533 \pm \\
0.0233\end{array}$ & $\begin{array}{l}0.1748 \pm \\
0.0180^{* *}\end{array}$ \\
\hline \multirow[t]{2}{*}{$\begin{array}{l}\% \text { to body } \\
\text { weight }\end{array}$} & Male & $\begin{array}{c}0.1269 \pm \\
0.0197\end{array}$ & $\begin{array}{c}0.0388 \pm \\
0.0074\end{array}$ & $\begin{array}{c}0.0332 \pm \\
0.0022\end{array}$ & $\begin{array}{c}0.1583 \pm \\
0.0338\end{array}$ & $\begin{array}{c}0.0437 \pm \\
0.0059\end{array}$ & $\begin{array}{c}0.1378 \pm \\
0.0261\end{array}$ & $\begin{array}{c}0.0433 \pm \\
0.0111\end{array}$ & $\begin{array}{c}0.1515 \pm \\
0.0229\end{array}$ & $\begin{array}{c}0.0424 \pm \\
0.0076\end{array}$ & $\begin{array}{l}0.0302 \pm \\
0.0073\end{array}$ \\
\hline & Female & $\begin{array}{c}0.1462 \pm \\
0.0121\end{array}$ & & & $\begin{array}{l}0.1739 \pm \\
0.0168^{* *}\end{array}$ & & & & & & $\begin{array}{l}0.0624 \pm \\
0.0057^{* *}\end{array}$ \\
\hline Prostate & Male & $\begin{array}{c}0.2664 \pm \\
0.0587\end{array}$ & $\begin{array}{l}0.5802 \pm \\
0.1913\end{array}$ & $\begin{array}{c}0.5616 \pm \\
0.1757\end{array}$ & $\begin{array}{c}0.3106 \pm \\
0.1454\end{array}$ & $\begin{array}{c}0.6464 \pm \\
0.1822\end{array}$ & $\begin{array}{c}0.3022 \pm \\
0.1208\end{array}$ & $\begin{array}{l}0.5570 \pm \\
0.1379\end{array}$ & $\begin{array}{c}0.2706 \pm \\
0.0913\end{array}$ & $\begin{array}{c}0.6609 \pm \\
0.1472\end{array}$ & $\begin{array}{l}0.5776 \pm \\
0.0680\end{array}$ \\
\hline $\begin{array}{c}\% \text { to body } \\
\text { weight }\end{array}$ & & $\begin{array}{c}0.0811 \pm \\
0.0150\end{array}$ & $\begin{array}{c}0.1215 \pm \\
0.0438\end{array}$ & $\begin{array}{c}0.1109 \pm \\
0.0312\end{array}$ & $\begin{array}{c}0.0950 \pm \\
0.0412\end{array}$ & $\begin{array}{c}0.1276 \pm \\
0.0318\end{array}$ & $\begin{array}{c}0.0921 \pm \\
0.0389\end{array}$ & $\begin{array}{c}0.1181 \pm \\
0.0294\end{array}$ & $\begin{array}{l}0.0825 \pm \\
0.0256\end{array}$ & $\begin{array}{c}0.1408 \pm \\
0.0278\end{array}$ & $\begin{array}{c}0.1141 \pm \\
0.0152\end{array}$ \\
\hline Testis (Lt.) & Male & $\begin{array}{l}1.8696 \pm \\
0.0630\end{array}$ & $\begin{array}{c}2.0628 \pm \\
0.1010\end{array}$ & $\begin{array}{c}2.2032 \pm \\
0.0711\end{array}$ & $\begin{array}{l}1.8118 \pm \\
0.2120\end{array}$ & $\begin{array}{c}2.1428 \pm \\
0.1616\end{array}$ & $\begin{array}{l}1.7334 \pm \\
0.2977\end{array}$ & $\begin{array}{c}1.9960 \pm \\
0.1191\end{array}$ & $\begin{array}{c}1.8244 \pm \\
0.0591\end{array}$ & $\begin{array}{c}2.1109 \pm \\
0.1282\end{array}$ & $\begin{array}{c}2.0692 \pm \\
0.1961\end{array}$ \\
\hline $\begin{array}{c}\% \text { to body } \\
\text { weight }\end{array}$ & & $\begin{array}{c}0.5739 \pm \\
0.0444\end{array}$ & $\begin{array}{c}0.4272 \pm \\
0.0342\end{array}$ & $\begin{array}{c}0.4385 \pm \\
0.0211\end{array}$ & $\begin{array}{l}0.5628 \pm \\
0.0395\end{array}$ & $\begin{array}{c}0.4264 \pm \\
0.0331\end{array}$ & $\begin{array}{c}0.5235 \pm \\
0.0758\end{array}$ & $\begin{array}{c}0.4242 \pm \\
0.0432\end{array}$ & $\begin{array}{c}0.5628 \pm \\
0.0349\end{array}$ & $\begin{array}{c}0.4522 \pm \\
0.0376\end{array}$ & $\begin{array}{l}0.4075 \pm \\
0.0315\end{array}$ \\
\hline Testis (Rt.) & Male & $\begin{array}{c}1.8672 \pm \\
0.0834\end{array}$ & $\begin{array}{c}2.0352 \pm \\
0.1580\end{array}$ & $\begin{array}{c}2.1622 \pm \\
0.0698\end{array}$ & $\begin{array}{l}1.8232 \pm \\
0.2055\end{array}$ & $\begin{array}{c}2.1153 \pm \\
0.1467\end{array}$ & $\begin{array}{c}1.7288 \pm \\
0.2737\end{array}$ & $\begin{array}{c}2.0206 \pm \\
0.1294\end{array}$ & $\begin{array}{l}1.8008 \pm \\
0.0563\end{array}$ & $\begin{array}{c}2.0990 \pm \\
0.1063\end{array}$ & $\begin{array}{c}2.0372 \pm \\
0.1672\end{array}$ \\
\hline $\begin{array}{c}\% \text { to body } \\
\text { weight }\end{array}$ & & $\begin{array}{c}0.5734 \pm \\
0.0512\end{array}$ & $\begin{array}{c}0.4218 \pm \\
0.0453\end{array}$ & $\begin{array}{c}0.4304 \pm \\
0.0209\end{array}$ & $\begin{array}{c}0.5664 \pm \\
0.0357\end{array}$ & $\begin{array}{c}0.4215 \pm \\
0.0376\end{array}$ & $\begin{array}{c}0.5226 \pm \\
0.0718\end{array}$ & $\begin{array}{c}0.4302 \pm \\
0.0524\end{array}$ & $\begin{array}{c}0.5553 \pm \\
0.0288\end{array}$ & $\begin{array}{c}0.4500 \pm \\
0.0388\end{array}$ & $\begin{array}{l}0.4021 \pm \\
0.0375\end{array}$ \\
\hline $\begin{array}{l}\text { Epididymis } \\
\text { (Lt.) }\end{array}$ & Male & $N D^{b)}$ & $\begin{array}{c}0.7142 \pm \\
0.0282\end{array}$ & $\begin{array}{c}0.7672 \pm \\
0.0424\end{array}$ & $N D^{b)}$ & $\begin{array}{c}0.7532 \pm \\
0.0594\end{array}$ & $N D^{b)}$ & $\begin{array}{c}0.7185 \pm \\
0.0632\end{array}$ & $N D^{\mathrm{b})}$ & $\begin{array}{c}0.7396 \pm \\
0.0401\end{array}$ & $\begin{array}{c}0.7240 \pm \\
0.0396\end{array}$ \\
\hline $\begin{array}{c}\% \text { to body } \\
\text { weight }\end{array}$ & & $N D^{b)}$ & & & $N D^{b)}$ & & $N D^{b)}$ & & & $\begin{array}{c}0.1584 \pm \\
0.0120\end{array}$ & $\begin{array}{c}0.1429 \pm \\
0.0097\end{array}$ \\
\hline $\begin{array}{l}\text { Epididymis } \\
\text { (Rt.) }\end{array}$ & Male & $N D^{b)}$ & $\begin{array}{c}0.7352 \pm \\
0.0372\end{array}$ & $\begin{array}{c}0.7620 \pm \\
0.0299\end{array}$ & $N D^{b)}$ & $\begin{array}{c}0.7572 \pm \\
0.0604\end{array}$ & $N D^{b)}$ & $\begin{array}{c}0.7429 \pm \\
0.0493\end{array}$ & $N D^{b)}$ & $\begin{array}{c}0.7501 \pm \\
0.0461\end{array}$ & $\begin{array}{c}0.7184 \pm \\
0.0322\end{array}$ \\
\hline $\begin{array}{c}\% \text { to body } \\
\text { weight }\end{array}$ & & $N D^{b)}$ & & & $N D^{b)}$ & & $N D^{b)}$ & & & $\begin{array}{c}0.1606 \pm \\
0.0127\end{array}$ & $\begin{array}{c}0.1417 \pm \\
0.0062\end{array}$ \\
\hline Ovary (Lt.) & Female & $\begin{array}{c}0.0443 \pm \\
0.0089\end{array}$ & $\begin{array}{c}0.0388 \pm \\
0.0120\end{array}$ & & $\begin{array}{c}0.0434 \pm \\
0.0037\end{array}$ & & & & & $\begin{array}{c}0.0403 \pm \\
0.0132\end{array}$ & $\begin{array}{c}0.0317 \pm \\
00129\end{array}$ \\
\hline $\begin{array}{c}\% \text { to body } \\
\text { weight }\end{array}$ & & $\begin{array}{c}0.0227 \pm \\
0.0040\end{array}$ & $\begin{array}{c}0.0143 \pm \\
0.0040\end{array}$ & $\begin{array}{c}0.0108 \pm \\
0.0023\end{array}$ & $\begin{array}{c}0.0223 \pm \\
0.0024\end{array}$ & & & $\begin{array}{c}0.0131 \pm \\
0.0033\end{array}$ & $\begin{array}{c}0.0210 \pm \\
0.0020\end{array}$ & $\begin{array}{c}0.0151 \pm \\
0.0044\end{array}$ & $\begin{array}{c}0.0114 \pm \\
0.0048\end{array}$ \\
\hline Ovary (Rt.) & Female & $\begin{array}{c}0.0453 \pm \\
0.0047\end{array}$ & & & & & & & & & $\begin{array}{c}0.0296 \pm \\
0.0078\end{array}$ \\
\hline $\begin{array}{c}\% \text { to body } \\
\text { weight }\end{array}$ & & $\begin{array}{c}0.0233 \pm \\
0.0023\end{array}$ & $\begin{array}{c}0.0139 \pm \\
0.0031\end{array}$ & $\begin{array}{c}0.0107 \pm \\
0.0035\end{array}$ & $\begin{array}{c}0.0221 \pm \\
0.0036\end{array}$ & & & $\begin{array}{c}0.0127 \pm \\
0.0031\end{array}$ & & $\begin{array}{c}0.0135 \pm \\
0.0034\end{array}$ & $\begin{array}{c}0.0106 \pm \\
0.0029\end{array}$ \\
\hline Uterus & Female & $\begin{array}{c}0.6020 \pm \\
0.5041\end{array}$ & $\begin{array}{l}0.7540 \pm \\
0.2803\end{array}$ & $\begin{array}{c}1.5136 \pm \\
1.7081\end{array}$ & $\begin{array}{c}0.7301 \pm \\
0.3711\end{array}$ & & $\begin{array}{c}0.4385 \pm \\
0.1144\end{array}$ & & & $\begin{array}{l}1.0180 \pm \\
0.7969\end{array}$ & $\begin{array}{c}0.7328 \pm \\
0.1301\end{array}$ \\
\hline $\begin{array}{c}\% \text { to body } \\
\text { weight }\end{array}$ & & $\begin{array}{c}0.3134 \pm \\
0.2721\end{array}$ & $\begin{array}{c}0.2805 \pm \\
0.1043\end{array}$ & $\begin{array}{c}0.5421 \pm \\
0.5875\end{array}$ & $\begin{array}{c}0.3756 \pm \\
0.1879\end{array}$ & $\begin{array}{c}0.2866 \pm \\
0.0986\end{array}$ & & $\begin{array}{c}0.2506 \pm \\
0.0902\end{array}$ & $\begin{array}{l}0.2244 \pm \\
0.0825\end{array}$ & $\begin{array}{c}0.3884 \pm \\
0.3038\end{array}$ & $\begin{array}{c}0.2615 \pm \\
0.0441\end{array}$ \\
\hline \multirow[t]{2}{*}{ Spleen } & Male & $\begin{array}{c}0.7080 \pm \\
0.0403\end{array}$ & $\begin{array}{c}0.8423 \pm \\
0.1620\end{array}$ & $\begin{array}{c}0.9244 \pm \\
0.1689\end{array}$ & $\begin{array}{c}0.7766 \pm \\
0.0442\end{array}$ & $\begin{array}{c}0.8627 \pm \\
0.1149\end{array}$ & $\begin{array}{c}0.8082 \pm \\
0.1229\end{array}$ & $\begin{array}{c}0.8115 \pm \\
0.1162\end{array}$ & $\begin{array}{c}0.6982 \pm \\
0.1578\end{array}$ & $\begin{array}{c}0.8396 \pm \\
0.0962\end{array}$ & $\begin{array}{c}0.9108 \pm \\
0.2680\end{array}$ \\
\hline & Female & $\begin{array}{l}0.5174 \pm \\
0.0475\end{array}$ & $\begin{array}{c}0.6023 \pm \\
0.0677\end{array}$ & $\begin{array}{c}0.5912 \pm \\
0.0969\end{array}$ & $\begin{array}{c}0.5178 \pm \\
0.0523\end{array}$ & $\begin{array}{c}0.5904 \pm \\
0.0496\end{array}$ & $\begin{array}{l}0.5450 \pm \\
0.0515\end{array}$ & $\begin{array}{c}0.5846 \pm \\
0.0497\end{array}$ & & $\begin{array}{l}0.5765 \pm \\
0.0545\end{array}$ & $\begin{array}{c}0.6338 \pm \\
0.0327\end{array}$ \\
\hline \multirow[t]{2}{*}{$\begin{array}{c}\% \text { to body } \\
\text { weight }\end{array}$} & Male & $\begin{array}{c}0.2167 \pm \\
0.0048\end{array}$ & $\begin{array}{c}0.1730 \pm \\
0.0254\end{array}$ & $\begin{array}{c}0.1838 \pm \\
0.0339\end{array}$ & $\begin{array}{c}0.2427 \pm \\
0.0232\end{array}$ & $\begin{array}{c}0.1712 \pm \\
0.0202\end{array}$ & $\begin{array}{c}0.2436 \pm \\
0.0258\end{array}$ & $\begin{array}{l}0.1712 \pm \\
0.0173\end{array}$ & $\begin{array}{c}0.2138 \pm \\
0.0418\end{array}$ & $\begin{array}{l}0.1796 \pm \\
0.0205\end{array}$ & $\begin{array}{c}0.1781 \pm \\
0.0461\end{array}$ \\
\hline & Female & $\begin{array}{c}0.2665 \pm \\
0.0256\end{array}$ & $\begin{array}{c}0.2239 \pm \\
0.0219\end{array}$ & $\begin{array}{c}0.2117 \pm \\
0.0160\end{array}$ & $\begin{array}{c}0.2655 \pm \\
0.0242\end{array}$ & $\begin{array}{c}0.2182 \pm \\
0.0115\end{array}$ & $\begin{array}{c}0.2778 \pm \\
0.0218\end{array}$ & $\begin{array}{c}0.2152 \pm \\
0.0231\end{array}$ & $\begin{array}{c}0.2786 \pm \\
0.0136\end{array}$ & $\begin{array}{c}0.2177 \pm \\
0.0161\end{array}$ & $\begin{array}{c}0.2264 \pm \\
0.0087\end{array}$ \\
\hline \multirow[t]{2}{*}{ Kidney (Lt.) } & Male & $\begin{array}{c}1.0834 \pm \\
0.0737\end{array}$ & $\begin{array}{l}1.4412 \pm \\
0.0916\end{array}$ & $\begin{array}{l}1.5350 \pm \\
0.1345\end{array}$ & $\begin{array}{c}1.1088 \pm \\
0.1901\end{array}$ & $\begin{array}{c}1.4725 \pm \\
0.2157\end{array}$ & $\begin{array}{c}1.1310 \pm \\
0.0947\end{array}$ & $\begin{array}{c}1.3753 \pm \\
0.1792\end{array}$ & $\begin{array}{c}1.0716 \pm \\
0.0701\end{array}$ & $\begin{array}{c}1.4461 \pm \\
0.3356\end{array}$ & $\begin{array}{l}1.4692 \pm \\
0.2390\end{array}$ \\
\hline & Female & $\begin{array}{c}0.6434 \pm \\
0.0440\end{array}$ & $\begin{array}{c}0.7791 \pm \\
0.0439\end{array}$ & $\begin{array}{c}0.8626 \pm \\
0.0847\end{array}$ & $\begin{array}{c}0.6320 \pm \\
0.0439\end{array}$ & $\begin{array}{c}0.7969 \pm \\
0.0477\end{array}$ & $\begin{array}{l}0.6650 \pm \\
0.0495\end{array}$ & $\begin{array}{c}0.8142 \pm \\
0.0688\end{array}$ & $\begin{array}{l}0.6674 \pm \\
0.0675\end{array}$ & $\begin{array}{l}0.8092 \pm \\
0.0705\end{array}$ & $\begin{array}{c}0.8742 \pm \\
0.0311\end{array}$ \\
\hline \multirow[t]{2}{*}{$\begin{array}{c}\% \text { to body } \\
\text { weight }\end{array}$} & Male & $\begin{array}{c}0.3318 \pm \\
0.0193\end{array}$ & $\begin{array}{c}0.2978 \pm \\
0.0159\end{array}$ & $\begin{array}{c}0.3050 \pm \\
0.0219\end{array}$ & $\begin{array}{c}0.3432 \pm \\
0.0376\end{array}$ & $\begin{array}{c}0.2910 \pm \\
0.0249\end{array}$ & $\begin{array}{l}0.3419 \pm \\
0.0083\end{array}$ & $\begin{array}{l}0.2899 \pm \\
0.0205\end{array}$ & $\begin{array}{c}0.3299 \pm \\
0.0131\end{array}$ & $\begin{array}{c}0.3073 \pm \\
0.0569\end{array}$ & $\begin{array}{c}0.2890 \pm \\
0.0406\end{array}$ \\
\hline & Female & $\begin{array}{c}0.3312 \pm \\
0.0210\end{array}$ & $\begin{array}{c}0.2901 \pm \\
0.0188\end{array}$ & $\begin{array}{c}0.3113 \pm \\
0.0296\end{array}$ & $\begin{array}{l}0.3238 \pm \\
0.0086\end{array}$ & $\begin{array}{c}0.2949 \pm \\
0.0128\end{array}$ & $\begin{array}{l}0.3387 \pm \\
0.0089\end{array}$ & $\begin{array}{l}0.2988 \pm \\
0.0206\end{array}$ & $\begin{array}{c}0.3417 \pm \\
0.0114\end{array}$ & $\begin{array}{c}0.3057 \pm \\
0.0212\end{array}$ & $\begin{array}{c}0.3124 \pm \\
0.0119\end{array}$ \\
\hline \multirow[t]{2}{*}{ Kidney (Rt.) } & Male & $\begin{array}{c}1.0920 \pm \\
0.0966\end{array}$ & $\begin{array}{c}1.4783 \pm \\
0.0904\end{array}$ & $\begin{array}{c}1.5424 \pm \\
0.1388\end{array}$ & $\begin{array}{c}1.0810 \pm \\
0.1098\end{array}$ & $\begin{array}{c}1.5046 \pm \\
0.2471\end{array}$ & $\begin{array}{c}1.1354 \pm \\
0.0658\end{array}$ & $\begin{array}{c}1.3637 \pm \\
0.1638\end{array}$ & $\begin{array}{l}1.0760 \pm \\
0.0876\end{array}$ & $\begin{array}{c}1.3921 \pm \\
0.1399\end{array}$ & $\begin{array}{l}1.4910 \pm \\
0.2666\end{array}$ \\
\hline & Female & $\begin{array}{l}0.6700 \pm \\
0.0245\end{array}$ & $\begin{array}{c}0.7974 \pm \\
0.0511\end{array}$ & $\begin{array}{c}0.8416 \pm \\
0.0896\end{array}$ & $\begin{array}{c}0.6542 \pm \\
0.0316\end{array}$ & $\begin{array}{c}0.8195 \pm \\
0.0634\end{array}$ & $\begin{array}{c}0.6956 \pm \\
0.0681\end{array}$ & $\begin{array}{c}0.8177 \pm \\
0.0871\end{array}$ & $\begin{array}{l}0.6604 \pm \\
0.0610\end{array}$ & $\begin{array}{c}0.8213 \pm \\
0.0652\end{array}$ & $\begin{array}{l}0.8740 \pm \\
0.0535\end{array}$ \\
\hline $\begin{array}{c}\% \text { to body } \\
\text { weight }\end{array}$ & Male & $\begin{array}{c}0.3345 \pm \\
0.0286\end{array}$ & $\begin{array}{c}0.3055 \pm \\
0.0175\end{array}$ & $\begin{array}{c}0.3064 \pm \\
0.0217\end{array}$ & $\begin{array}{c}0.3361 \pm \\
0.0184\end{array}$ & $\begin{array}{c}0.2969 \pm \\
0.0260\end{array}$ & $\begin{array}{c}0.3437 \pm \\
0.0108\end{array}$ & $\begin{array}{c}0.2879 \pm \\
0.0218\end{array}$ & $\begin{array}{c}0.3310 \pm \\
0.0159\end{array}$ & $\begin{array}{c}0.2969 \pm \\
0.0165\end{array}$ & $\begin{array}{c}0.2931 \pm \\
0.0453\end{array}$ \\
\hline
\end{tabular}


Table 5 Absolute \& relative organ weights in rats orally treated with PM012 (Continued)

\begin{tabular}{|c|c|c|c|c|c|c|c|c|c|c|c|}
\hline & Female & $\begin{array}{c}0.3451 \pm \\
0.0156\end{array}$ & $\begin{array}{c}0.2967 \pm \\
0.0179\end{array}$ & $\begin{array}{c}0.3030 \pm \\
0.0199\end{array}$ & $\begin{array}{c}0.3355 \pm \\
0.0096\end{array}$ & $\begin{array}{c}0.3032 \pm \\
0.0199\end{array}$ & $\begin{array}{c}0.3539 \pm \\
0.0160\end{array}$ & $\begin{array}{c}0.2997 \pm \\
0.0257\end{array}$ & $\begin{array}{c}0.3382 \pm \\
0.0090\end{array}$ & $\begin{array}{c}0.3104 \pm \\
0.0204\end{array}$ & $\begin{array}{c}0.3125 \pm \\
0.0224\end{array}$ \\
\hline \multirow[t]{2}{*}{ Heart } & Male & $\begin{array}{c}1.1572 \pm \\
0.0898\end{array}$ & $\begin{array}{l}1.6088 \pm \\
0.1665\end{array}$ & $\begin{array}{c}1.5266 \pm \\
0.1471\end{array}$ & $\begin{array}{l}1.1302 \pm \\
0.2075\end{array}$ & $\begin{array}{l}1.5934 \pm \\
0.1625\end{array}$ & $\begin{array}{c}1.1730 \pm \\
0.0850\end{array}$ & $\begin{array}{c}1.4677 \pm \\
0.1040\end{array}$ & $\begin{array}{c}1.1562 \pm \\
0.0871\end{array}$ & $\begin{array}{c}1.5236 \pm \\
0.1646\end{array}$ & $\begin{array}{c}1.5334 \pm \\
0.2367\end{array}$ \\
\hline & Female & $\begin{array}{c}0.7574 \pm \\
0.0447\end{array}$ & $\begin{array}{c}0.9366 \pm \\
0.0652\end{array}$ & $\begin{array}{c}0.9298 \pm \\
0.1196\end{array}$ & $\begin{array}{c}0.7590 \pm \\
0.0380\end{array}$ & $\begin{array}{c}0.9729 \pm \\
0.0742\end{array}$ & $\begin{array}{c}0.7254 \pm \\
0.0599\end{array}$ & $\begin{array}{c}0.9469 \pm \\
0.0530\end{array}$ & $\begin{array}{c}0.7158 \pm \\
0.0575\end{array}$ & $\begin{array}{c}1.0124 \pm \\
0.3391\end{array}$ & $\begin{array}{l}0.9704 \pm \\
0.0845\end{array}$ \\
\hline \multirow[t]{2}{*}{$\begin{array}{l}\% \text { to body } \\
\text { weight }\end{array}$} & Male & $\begin{array}{c}0.3543 \pm \\
0.0229\end{array}$ & $\begin{array}{c}0.3317 \pm \\
0.0228\end{array}$ & $\begin{array}{c}0.3034 \pm \\
0.0256\end{array}$ & $\begin{array}{l}0.3499 \pm \\
0.0445\end{array}$ & & $\begin{array}{c}0.3551 \pm \\
0.0177\end{array}$ & & $\begin{array}{c}0.3560 \pm \\
0.0208\end{array}$ & & $\begin{array}{c}0.3010 \pm \\
0.0324\end{array}$ \\
\hline & Female & $\begin{array}{c}0.3896 \pm \\
0.0119\end{array}$ & $\begin{array}{l}0.3484 \pm \\
0.0209\end{array}$ & $\begin{array}{c}0.3344 \pm \\
0.0242\end{array}$ & $\begin{array}{c}0.3893 \pm \\
0.0152\end{array}$ & $\begin{array}{l}0.3601 \pm \\
0.0259\end{array}$ & $\begin{array}{c}0.3705 \pm \\
0.0346\end{array}$ & $\begin{array}{c}0.3477 \pm \\
0.0142\end{array}$ & $\begin{array}{c}0.3683 \pm \\
0.0374\end{array}$ & $\begin{array}{l}0.3845 \pm \\
0.1360\end{array}$ & $\begin{array}{l}0.3465 \pm \\
0.0266\end{array}$ \\
\hline \multirow[t]{2}{*}{ Lung } & Male & $\begin{array}{c}1.5656 \pm \\
0.0698\end{array}$ & $\begin{array}{l}1.9947 \pm \\
0.1779\end{array}$ & $\begin{array}{c}2.0066 \pm \\
0.1561\end{array}$ & $\begin{array}{c}1.4874 \pm \\
0.1229\end{array}$ & $\begin{array}{c}2.0049 \pm \\
0.1510\end{array}$ & $\begin{array}{l}1.5250 \pm \\
0.1239\end{array}$ & $\begin{array}{l}1.8534 \pm \\
0.1209\end{array}$ & $\begin{array}{c}1.5416 \pm \\
0.1092\end{array}$ & $\begin{array}{l}1.9613 \pm \\
0.1305\end{array}$ & $\begin{array}{c}1.8042 \pm \\
0.1591\end{array}$ \\
\hline & Female & $\begin{array}{c}1.1890 \pm \\
0.0432\end{array}$ & $\begin{array}{c}1.4361 \pm \\
0.1088\end{array}$ & $\begin{array}{l}1.4584 \pm \\
0.1603\end{array}$ & $\begin{array}{c}1.2182 \pm \\
0.1431\end{array}$ & $\begin{array}{c}1.4594 \pm \\
0.0892\end{array}$ & $\begin{array}{c}1.2164 \pm \\
0.1588\end{array}$ & $\begin{array}{c}1.4234 \pm \\
0.0721\end{array}$ & $\begin{array}{c}1.1466 \pm \\
0.0518\end{array}$ & $\begin{array}{c}1.4478 \pm \\
0.1077\end{array}$ & $\begin{array}{l}1.4262 \pm \\
0.1322\end{array}$ \\
\hline \multirow[t]{2}{*}{$\begin{array}{l}\% \text { to body } \\
\text { weight }\end{array}$} & Male & $\begin{array}{c}0.4797 \pm \\
0.0204\end{array}$ & $\begin{array}{c}0.4114 \pm \\
0.0208\end{array}$ & $\begin{array}{c}0.3987 \pm \\
0.0234\end{array}$ & $\begin{array}{c}0.4637 \pm \\
0.0366\end{array}$ & $\begin{array}{c}0.3982 \pm \\
0.0178\end{array}$ & $\begin{array}{c}0.4610 \pm \\
0.0128\end{array}$ & $\begin{array}{c}0.3923 \pm \\
0.0204\end{array}$ & $\begin{array}{c}0.4744 \pm \\
0.0180\end{array}$ & $\begin{array}{l}0.4205 \pm \\
0.0415\end{array}$ & $\begin{array}{l}0.3571 \pm \\
0.0440\end{array}$ \\
\hline & Female & $\begin{array}{l}0.6121 \pm \\
0.0203\end{array}$ & $\begin{array}{l}0.5337 \pm \\
0.0229\end{array}$ & $\begin{array}{c}0.5264 \pm \\
0.0574\end{array}$ & $\begin{array}{c}0.6234 \pm \\
0.0522\end{array}$ & $\begin{array}{l}0.5403 \pm \\
0.0305\end{array}$ & $\begin{array}{l}0.6207 \pm \\
0.0833\end{array}$ & $\begin{array}{l}0.5233 \pm \\
0.0339\end{array}$ & $\begin{array}{l}0.5891 \pm \\
0.0283\end{array}$ & $\begin{array}{l}0.5469 \pm \\
0.0270\end{array}$ & $\begin{array}{l}0.5094 \pm \\
0.0439\end{array}$ \\
\hline \multirow[t]{2}{*}{ Brain } & Male & $N D^{b)}$ & $\begin{array}{c}2.0641 \pm \\
0.0562\end{array}$ & $\begin{array}{c}2.0344 \pm \\
0.0501\end{array}$ & NDb) & $\begin{array}{c}2.0215 \pm \\
0.0849\end{array}$ & NDb) & $\begin{array}{l}1.9862 \pm \\
0.0473\end{array}$ & $\mathrm{NDb)}$ & $\begin{array}{l}2.0204 \pm \\
0.0423\end{array}$ & $\begin{array}{c}2.0450 \pm \\
0.0802\end{array}$ \\
\hline & Female & $N D^{b)}$ & $\begin{array}{c}1.8062 \pm \\
0.0368\end{array}$ & $\begin{array}{l}1.8284 \pm \\
0.0730\end{array}$ & NDb) & $\begin{array}{l}1.8646 \pm \\
0.0732\end{array}$ & NDb) & $\begin{array}{c}1.8016 \pm \\
0.0678\end{array}$ & NDb) & $\begin{array}{l}1.8069 \pm \\
0.0602\end{array}$ & $\begin{array}{l}1.8722 \pm \\
0.0673\end{array}$ \\
\hline \multirow[t]{2}{*}{$\begin{array}{c}\% \text { to body } \\
\text { weight }\end{array}$} & Male & $N D^{b)}$ & $\begin{array}{c}0.4275 \pm \\
0.0298\end{array}$ & $\begin{array}{c}0.4048 \pm \\
0.0137\end{array}$ & NDb) & $\begin{array}{l}0.4026 \pm \\
0.0255\end{array}$ & NDb) & $\begin{array}{c}0.4220 \pm \\
0.0351\end{array}$ & $\mathrm{NDb)}$ & $\begin{array}{c}0.4329 \pm \\
0.0277\end{array}$ & $\begin{array}{c}0.4042 \pm \\
0.0335\end{array}$ \\
\hline & Female & $N D^{b)}$ & $\begin{array}{c}0.6726 \pm \\
0.0258\end{array}$ & $\begin{array}{c}0.6629 \pm \\
0.0681\end{array}$ & NDb) & $\begin{array}{c}0.6902 \pm \\
0.0214\end{array}$ & NDb) & $\begin{array}{c}0.6628 \pm \\
0.0431\end{array}$ & NDb) & $\begin{array}{l}0.6841 \pm \\
0.0382\end{array}$ & $\begin{array}{c}0.6695 \pm \\
0.0368\end{array}$ \\
\hline \multirow[t]{2}{*}{ Liver } & Male & $\begin{array}{c}9.5912 \pm \\
0.7911\end{array}$ & $\begin{array}{c}11.8528 \pm \\
1.1643\end{array}$ & $\begin{array}{c}12.6104 \pm \\
1.7035\end{array}$ & $\begin{array}{c}9.3626 \pm \\
0.9629\end{array}$ & $\begin{array}{c}12.5935 \pm \\
2.2636\end{array}$ & $\begin{array}{c}10.1466 \pm \\
0.5700\end{array}$ & $\begin{array}{c}11.1793 \pm \\
1.7555\end{array}$ & $\begin{array}{c}9.5052 \pm \\
0.5582\end{array}$ & $\begin{array}{c}11.0740 \pm \\
0.9159\end{array}$ & $\begin{array}{c}13.0788 \pm \\
2.8997\end{array}$ \\
\hline & Female & $\begin{array}{c}5.5920 \pm \\
0.5099\end{array}$ & $\begin{array}{c}6.4589 \pm \\
0.7810\end{array}$ & $\begin{array}{c}6.4812 \pm \\
0.6049\end{array}$ & $\begin{array}{c}5.5784 \pm \\
0.5334\end{array}$ & $\begin{array}{c}6.8322 \pm \\
1.1330\end{array}$ & $\begin{array}{c}5.5102 \pm \\
0.3767\end{array}$ & $\begin{array}{c}6.8610 \pm \\
1.7458\end{array}$ & $\begin{array}{c}5.5738 \pm \\
0.5615\end{array}$ & $\begin{array}{c}6.6866 \pm \\
0.5558\end{array}$ & $\begin{array}{c}6.6626 \pm \\
0.9795\end{array}$ \\
\hline \multirow[t]{2}{*}{$\begin{array}{l}\% \text { to body } \\
\text { weight }\end{array}$} & Male & $\begin{array}{l}2.9356 \pm \\
0.1935\end{array}$ & $\begin{array}{c}2.4422 \pm \\
0.1178\end{array}$ & $\begin{array}{c}2.5046 \pm \\
0.3008\end{array}$ & $\begin{array}{c}2.9083 \pm \\
0.1159\end{array}$ & $\begin{array}{c}2.4815 \pm \\
0.2634\end{array}$ & $\begin{array}{c}3.0727 \pm \\
0.1101\end{array}$ & $\begin{array}{c}2.3528 \pm \\
0.2271\end{array}$ & $\begin{array}{c}2.9256 \pm \\
0.0668\end{array}$ & $\begin{array}{l}2.3638 \pm \\
0.1116\end{array}$ & $\begin{array}{l}2.5611 \pm \\
0.4535\end{array}$ \\
\hline & Female & $\begin{array}{c}2.8812 \pm \\
0.2921\end{array}$ & $\begin{array}{c}2.3981 \pm \\
0.2116\end{array}$ & $\begin{array}{c}2.3332 \pm \\
0.0680\end{array}$ & $\begin{array}{c}2.8595 \pm \\
0.2334\end{array}$ & $\begin{array}{c}2.5241 \pm \\
0.3756\end{array}$ & $\begin{array}{c}2.8115 \pm \\
0.1862\end{array}$ & $\begin{array}{c}2.4970 \pm \\
0.4764\end{array}$ & $\begin{array}{c}2.8554 \pm \\
0.1547\end{array}$ & $\begin{array}{c}2.5322 \pm \\
0.2457\end{array}$ & $\begin{array}{c}2.3763 \pm \\
0.3002\end{array}$ \\
\hline
\end{tabular}

a) Represents body weights right before necropsy, after fasting.

b) ND, not determined.

Values are mean \pm SD ( $n=5$ ( 4 weeks or recovery) or 10 ( 26 weks)/sex/dose). $P<0.05$ compare with normal group.

luteum cyst observed in female ovaries are all spontaneous lesions $[38,39,41]$. All of these conditions are readily detected in old rats and were not considered to be changes triggered by the administration of PM012 based on the comparison to the vehicle control group.

Other anomalies were determined to be unrelated to the administration of PM012. In females, an enlargement of uterine cavity, hydrometra, was observed in similar frequency in the vehicle control group, and because no other lesions were observed in the uterus, such as in the endometrial epithelium or myometrial area, it was judged that these changes were not triggered by the administration of PM012 and were considered as changes related to the regular sexual cycle [41]. No cellular reaction to a hemorrhage in the parenchyma of the thymus was observed, and a hemorrhage is a lesion that is often seen after etherization and therefore was not considered to be an effect of the administration of
PM012 [41]. A benign ganglioneuroma derived from adrenal medulla cells and consisting of histopathologically proliferative big ganglion cells and interstitial nervous tissue such as Schwann cells, satellite cells and nerve fibers was observed in a male treated with 2,000 $\mathrm{mg} / \mathrm{kg} /$ day. The tumors observed in this study were observed to be over $80 \%$ ganglioneuromas and the rest had the histological features of pheochromocytomas. In this case, it is reasonable to diagnose these tumors as ganglioneuromas rather than complex pheochromocytomas, as this type of tumors is seldom found in old rats [38]. The fibroadenoma observed in the mammary gland of the skin in a female from the middle dose group was a benign tumor derived from the mammary epithelium and connective tissue, which is observed at a high frequency in rats and was judged to have occurred spontaneously and therefore was unrelated to treatment with PM012 [38,39]. We also found that the 4- or 26-week 
repeated oral administration of PM012 in male and female rats induced an increase and increasing trend in the weight of the thymus in the female treatment groups (main and recovery groups), but the change was judged to be toxicologically insignificant.

\section{Conclusion}

Given our evaluation of all the data, the no observed adverse effects levels (NOAEL) of PM012 was determined to be $2,000 \mathrm{mg} / \mathrm{kg} /$ day for both sexes, and the target organ was not identified. We conclude that PM012 has potential for use in the treatment of the Alzheimer's disease without serious adverse effects.

\section{Additional material}

Additional file 1: Table S1. Urinalysis in rats orally treated with PM012.

\begin{abstract}
Abbreviations
hPS2m: Human presenilin 2 mutant transgenic mice; AD: Alzheimer's disease; ACh: Acetylcholine; ChAT: Choline acetyltransferase; $\beta$-APP: $\beta$-amyloid precursor protein; PS1: Presenilin 1; PS2: Presenilin 2; APOE-E4: Apolipoprotein E type 4; YMJ: Yukmijihwang-tang or Luweidihuang-wang; PM012: YMJ derivatives; WBC: White blood cell; RBC: Red blood cell; HGB: Hemoglobin concentration; HCT: Hematocrit; MCV: Mean corpuscular volume; MCH: Mean corpuscular hemoglobin; MCHC: Mean corpuscular hemoglobin concentration; RDW: Red cell distribution width; PLT: Platelet; MPV: Mean platelet volume; RET: Reticulocyte; NEU: Neutrophil; LYM: Lymphocyte; MONO: Monocyte; EOS: Eosinophil; BASO: Basophil; AST: Aspartate aminotransferase; ALT: Alanine aminotransferase; ALP: Alkaline phosphatase; CPK: Creatine phosphokinase; BIL: Total bilirubin; GLU: Glucose; CHO: Total cholesterol; TG: Triglyceride; PRO: Total protein; ALB: Albumin; A/ $G$ ratio: Albumin/Globulin ratio; BUN: Blood urea nitrogen; CRE: Creatinine; IP: Inorganic phosphorus.
\end{abstract}

\section{Acknowledgements}

This study was supported by a grant of the Traditional Korean Medicine R\&D Project, Ministry for Health \& Welfare, Republic of Korea. (B110025)

\section{Author details}

${ }^{1}$ Department of Physiology, College of Oriental Medicine, Kyung Hee University, Hoegi-dong, Seoul, Dongdaemun-gu 130-701, Republic of Korea.

${ }^{2}$ Present address: Department of Psychiatry, Seoul St. Mary's Hospital, College of Medicine, The Catholic University of Korea, 505 Banpo-dong, Seoul, Seocho-gu 137-701, Republic of Korea.

\section{Authors' contributions}

All authors participated in the acquisition of data and revision of the manuscript. All authors conceived of the study, determined the design, interpreted the data and drafted the manuscript. All authors read and gave final approval for the version submitted for publication.

\section{Competing interests}

The authors declare that they have no competing interests.

Received: 30 December 2011 Accepted: 29 March 2012 Published: 29 March 2012

\section{References}

1. Watanabe CM, Wolffram S, Ader P, Rimbach G, Packer L, Maguire JJ, Schultz PG, Gohil K: The in vivo neuromodulatory effects of the herbal medicine ginkgo biloba. Proc Natl Acad Sci USA 2001, 98(12):6577-6580.
2. Cui Y, Yan Z, Hou S, Chang Z: Effect of radix Rehmanniae preparata on the expression of c-fos and NGF in hippocampi and learning and memory in rats with damaged thalamic arcuate nucleus. Zhong Yao Cai 2004, 27(8):589-592.

3. Cui Y, Yan ZH, Hou SL, Chang ZF: [Intelligence enhancement of radix Rehmanniae praeparata and some comments on its research]. Zhongguo Zhong Yao Za Zhi 2002, 27(6):404-406, 456.

4. Ren B, Ma Y, Shen Y, Gao B: [Protective action of Lycium barbarum L. $(\mathrm{LbL})$ and betaine on lipid peroxidation of erythrocyte membrane induced by H2O2]. Zhongguo Zhong Yao Za Zhi 1995, 20(5):303-304, inside cover.

5. Mau JL, Chao GR, Wu KT: Antioxidant properties of methanolic extracts from several ear mushrooms. J Agric Food Chem 2001, 49(11):5461-5467.

6. Sherrington R, Rogaev El, Liang Y, Rogaeva EA, Levesque G, Ikeda M, Chi $H$, Lin C, Li G, Holman K, et al: Cloning of a gene bearing missense mutations in early-onset familial Alzheimer's disease. Nature 1995, 375(6534):754-760.

7. Corder EH, Saunders AM, Strittmatter WJ, Schmechel DE, Gaskell PC, Small GW, Roses AD, Haines JL, Pericak-Vance MA: Gene dose of apolipoprotein E type 4 allele and the risk of Alzheimer's disease in late onset families. Science 1993, 261(5123):921-923.

8. Strittmatter WJ, Roses AD: Apolipoprotein E and Alzheimer disease. Proc Natl Acad Sci USA 1995, 92(11):4725-4727.

9. Rogaev El, Sherrington R, Rogaeva EA, Levesque G, Ikeda M, Liang Y, Chi H, Lin C, Holman K, Tsuda T, et al: Familial Alzheimer's disease in kindreds with missense mutations in a gene on chromosome 1 related to the Alzheimer's disease type 3 gene. Nature 1995, 376(6543):775-778.

10. Goate A, Chartier-Harlin MC, Mullan M, Brown J, Crawford F, Fidani L, Giuffra L, Haynes A, Irving N, James L, et al: Segregation of a missense mutation in the amyloid precursor protein gene with familial Alzheimer's disease. Nature 1991, 349(6311):704-706.

11. Wasco W, Pettingell WP, Jondro PD, Schmidt SD, Gurubhagavatula S, Rodes L, DiBlasi T, Romano DM, Guenette SY, Kovacs DM, et al: Familial Alzheimer's chromosome 14 mutations. Nat Med 1995, 1(9):848.

12. Derby R, Lee SH, Seo KS, Kazala K, Kim BJ, Kim MJ: Efficacy of IDET for relief of leg pain associated with discogenic low back pain. Pain Pract 2004, 4(4):281-285.

13. Park E, Kum S, Wang C, Park SY, Kim BS, Schuller-Levis G: Anti-inflammatory activity of herbal medicines: inhibition of nitric oxide production and tumor necrosis factor-alpha secretion in an activated macrophage-like cell line. Am J Chin Med 2005, 33(3):415-424.

14. Dieter MP, Boorman GA, Jameson CW, Matthews HB, Huff JE: The carcinogenic activity of commercial grade toluene diisocyanate in rats and mice in relation to the metabolism of the 2,4- and 2,6-TDI isomers. Toxicol Ind Health 1990, 6(6):599-621.

15. Kang M, Kim JH, Cho C, Lee KY, Shin M, Hong M, Shim I, Bae H: Effects of Yukmijihwang-tang derivatives (YMJd) on ibotenic acid-induced amnesia in the rat. Biol Pharm Bull 2006, 29(7):1431-1435.

16. Higgins JP, Flicker L: Lecithin for dementia and cognitive impairment. Cochrane Database Syst Rev 2003, 3:CD001015.

17. Hoye AT, Davoren JE, Wipf P, Fink MP, Kagan VE: Targeting mitochondria. Acc Chem Res 2008, 41(1):87-97.

18. Kim JH, Kang M, Cho C, Chung HS, Kang CW, Parvez S, Bae H: Effects of Nelumbinis Semen on contractile dysfunction in ischemic and reperfused rat heart. Arch Pharm Res 2006, 29(9):777-785.

19. Kim JK, Kim DM, Kang MS, Kim HK, Kim JS, Yu EK, Jeong JH: Gadoliniumchlorin is potentially a new tumor specific MRI contrast agent. Arch Pharm Res 2006, 29(3):188-190.

20. Korea Food and Drug Administration: Good Laboratory Practice (GLP), Notification No. 2005-79, Toxicity Test Guidelines for Safety Evaluation of Drugs. 2005.

21. Dai $Y$, But PP, Chan YP, Matsuda H, Kubo M: Antipruritic and antiinflammatory effects of aqueous extract from Si-Wu-Tang. Biol Pharm Bull 2002, 25(9):1175-1178.

22. U.S. Food and Drug Administration: Toxicological Principles for the Safety Assessment of Food Ingredients, IV.C.3a Short-Term Toxicity Studies with Rodents. Redbook 20002003.

23. Korea Food and Drug Administration: The Standards of Toxicity Study for Medicinal Products, Notification No. 2005-60. 2005

24. Morris R: Developments of a water-maze procedure for studying spatial learning in the rat. J Neurosci Methods 1984, 11(1):47-60. 
25. Kim J, Lee H, Lee Y, Oh BG, Cho C, Kim Y, Shin M, Hong M, Jung SK, Bae H: Inhibition effects of Moutan Cortex Radicis on secretion of eotaxin in A549 human epithelial cells and eosinophil migration. J Ethnopharmacol 2007, 114(2):186-193.

26. Hu Y, Hou TT, Xin HL, Zhang QY, Zheng HC, Rahman K, Qin LP: Estrogenlike activity of volatile components from Vitex rotundifolia L. Indian J Med Res 2007, 126(1):68-72

27. Rho S, Kang M, Choi B, Sim D, Lee J, Lee E, Cho C, Oh JW, Park S, Ko S, et al: Effects of Yukmijihwang-tang derivatives (YMJd), a memory enhancing herbal extract, on the gene-expression profile in the rat hippocampus. Biol Pharm Bull 2005, 28(1):87-93.

28. Park E, Kang M, Oh JW, Jung M, Park C, Cho C, Kim C, Ji S, Lee Y, Choi H, et al: Yukmijihwang-tang derivatives enhance cognitive processing in normal young adults: a double-blinded, placebo-controlled trial. Am J Chin Med 2005, 33(1):107-115.

29. Rho S, Chung HS, Kang M, Lee E, Cho C, Kim H, Park S, Kim HY, Hong M, Shin $M$, et al: Inhibition of production of reactive oxygen species and gene expression profile by treatment of ethanol extract of Moutan Cortex Radicis in oxidative stressed PC12 cells. Biol Pharm Bull 2005, 28(4):661-666.

30. Mau J, Chen C, Hsieh P: Antimicrobial effect of extracts from Chinese chive, cinnamon, and corni fructus. J Agric Food Chem 2001, 49(1):183-188

31. Wei RB, Huo HR, Li XQ, Zhou AX, Shen H, Tian JL: Study on antiinflammatory effect of a compound TCM agent containing ant extractive in animal models. Zhongguo Zhong Yao Za Zhi 2002, 27(3):215-218

32. Dai $Y$, Hang B, Huang Z: [Inhibition of fructus Corni on experimental inflammation]. Zhongguo Zhong Yao Za Zhi 1992, 17(5):307-309, backcover.

33. Kim MJ, Kim HN, Kang KS, Baek NI, Kim DK, Kim YS, Jeon BH, Kim SH: Methanol extract of Dioscoreae Rhizoma inhibits pro-inflammatory cytokines and mediators in the synoviocytes of rheumatoid arthritis. Int Immunopharmacol 2004, 4(12):1489-1497.

34. Park WH, Joo ST, Park KK, Chang YC, Kim CH: Effects of the Geiji-BokryungHwan on carrageenan-induced inflammation in mice and cyclooxygenase-2 in hepatoma cells of HepG2 and Hep3B. Immunopharmacol Immunotoxicol 2004, 26(1):103-112.

35. Gillette Guyonnet $\mathrm{S}$, Abellan Van Kan G, Alix E, Andrieu S, Belmin J, Berrut G, Bonnefoy M, Brocker P, Constans T, Ferry M, et al: IANA (International Academy on Nutrition and Aging) Expert Group: weight loss and Alzheimer's disease. J Nutr Health Aging 2007, 11(1):38-48.

36. Belmin J: Practical guidelines for the diagnosis and management of weight loss in Alzheimer's disease: a consensus from appropriateness ratings of a large expert panel. J Nutr Health Aging 2007, 11(1):33-37.

37. Harada T, Maronpot RR, Morris RW, Boorman GA: Effects of mononuclear cell leukemia on altered hepatocellular foci in Fischer 344 rats. Vet Pathol 1990, 27(2):110-116.

38. Boorman GA, Eustis SL, Elwell MR, Montgomery CA Jr, Mackenzie WF: Pathology of the Fischer Rat San Diego: Academic Press; 1990.

39. Greaves P: Histopathology of preclinical toxicity studies; Interpretation and relevance in drug evaluation New York: Elsevier; 2000.

40. Sellers RS, Morton D, Michael B, Roome N, Johnson JK, Yano BL, Perry R, Schafer K: Society of Toxicologic Pathology position paper: organ weight recommendations for toxicology studies. Toxicol Pathol 2007, 35(5):751-755.

41. Makoto E, Kaneyoshi A: Color atlas of toxicological pathology-Fundamental of morphological observation Tokyo: Soft Science Publications; 1987.

\section{Pre-publication history}

The pre-publication history for this paper can be accessed here: http://www.biomedcentral.com/1472-6882/12/24/prepub

doi:10.1186/1472-6882-12-24

Cite this article as: Sohn et al: Safety and efficacy assessment of standardized herbal formula PM012. BMC Complementary and Alternative Medicine 2012 12:24.

\section{Submit your next manuscript to BioMed Central and take full advantage of:}

- Convenient online submission

- Thorough peer review

- No space constraints or color figure charges

- Immediate publication on acceptance

- Inclusion in PubMed, CAS, Scopus and Google Scholar

- Research which is freely available for redistribution

Submit your manuscript at www.biomedcentral.com/submit
Biomed Central 